\title{
Simulation of Optimal Harvesting of Three Species Ecological Model with Closed Interval of Biological Parameter using by using First Order Nonlinear Ordinary Differential Equations
}

\author{
Tadesse Lamessa Edae ${ }^{1} \quad$ Selashi Dabi ${ }^{2}$ \\ 1.College of Natural and Computational science, Department of Applied Mathematics Wolaita Sodo University, \\ sodo Ethiopia, Lecturer of Differential equation \\ 2.College of Natural and Computational science, Department of Applied Mathematics Wolaita sodo university, \\ sodo Ethiopia lecturer of Number Theory
}

\begin{abstract}
The paper presents the study of three species ecological model with Prey $\mathrm{N}_{1}$, predator $\mathrm{N}_{2}$ and competitor to the Predator $\mathrm{N}_{3}$ and neutral with the predator $\mathrm{N}_{2}$ with imprecise biological parameters. The model is characterized by a set of first order nonlinear ordinary differential equations. Due to the lack of precise numerical information of the biological parameters such as prey population growth rate, predator population decay rate and predation coefficients, we consider the model with imprecise data as form of an interval in nature. Many authors have studied prey-predator harvesting model in different form, here we consider a simple prey-predator model under impreciseness and introduce parametric functional form of an interval and then study the model. Equilibrium points of the model are identified, the local stability is discussed using Routh - Hurwitz criteria and global stability by Liapunov function. The existence of bionomic equilibrium of the system has been discussed and optimal harvesting policy is given using Pontryagin's maximum principle. The stability analysis is supported by Numerical simulation using Mat lab.
\end{abstract}

Keywords: Prey; Predator; Competitor to the predator; Equilibrium points; interval number, Stability of the equilibrium points; Bionomic Equilibrium; Optimal harvesting policy; Pontryagin's maximum principle; Numerical simulation using mat lab.

DOI: $10.7176 / \mathrm{JAAS} / 52-02$

\section{INTRODUCTION}

\section{Background}

Mathematical modeling of ecosystems is a field of study which helps us to understand the interactions between different species and the mechanisms that influence the growth of species and their existence and stability. Mathematical models have been used to study the dynamics of prey-predator systems since Lotka (1925) and Volterra (1927). They proposed the simple mathematical model which describes the interaction between prey and the predator. Since then, many mathematical models have been constructed based on more realistic explicit and implicit biological assumptions.

Mathematical modeling is a frequently evolving process, to gain a deep understanding of the mathematical aspects of the problem and to yield non trivial biological insights; one must carefully construct biologically meaningful and mathematically tractable population models. Some of the aspects that need to be critically considered in a realistic and plausible mathematical model include; carrying capacity which is the maximum number of prey that the ecosystem can sustain in the absence of predator, competition among prey and predators which can be intraspecific or inter specific, harvesting of prey or predators and functional responses of the predators.

In this research work, a mathematical model to study the ecological dynamics of prey and predator system is proposed and analyzed. And also as an example some of the prey and predator system in some areas be studied.

\subsection{Pre-Requisite Mathematics}

\subsubsection{Interval Number}

Interval arithmetic, interval mathematics, interval analysis, or interval computation, is a method developed by mathematicians since the $1950 \mathrm{~s}$ and $1960 \mathrm{~s}$ as an approach to putting bounds on rounding errors and measurement errors in mathematical computation and thus developing numerical methods that yield reliable results. Very simply, it represents each value as a range of possibilities. For example, instead of estimating the height of someone using standard arithmetic as 2.0 meters, using interval arithmetic we might be certain that person is somewhere between 1.97 and 2.03 meters.

An interval number $\mathrm{A}$ is represented by closed interval $\left[a_{l}, a_{r}\right]$ and defined by:

$$
A=\left[a_{l}, a_{r}\right]=\left\{x: a_{l} \leq x \leq a_{r}, x \in \mathrm{R}\right\}
$$

Where $R$ is the set of real numbers and $a_{l}, a_{r}$ are the left and right limit of the interval number respectively. Also every real number $a$ can be represented by the interval number as $[a, a]$ for all 
$a \in R$

Classical arithmetic defines operations on individual numbers; interval arithmetic defines a set of operations on intervals.

$T \cdot S=\{x \mid$ there is some $y$ in $T$, and some $z$ in $S$, such that $x=y \cdot z\}$.

The basic operations of interval arithmetic are, for two intervals $[a, b]$ and $[\mathrm{c}, \mathrm{d}]$ that are subsets of the real line $(-\infty, \infty)$,

$$
\begin{array}{lll}
\text { i. } & {[a, b]+[c, d]=[a+c, b+d],} \\
\text { ii. } & {[a, b]-[c, d]=[a-c, b-d],}
\end{array}
$$

iii. $[a, b] \times[c, d]=[\min \{a \times c, a \times d, b \times c, b \times d\}, \max \{a \times c, a \times d, b \times c, b \times d\}]$

iv. $[a, b] \div[c, d]=[\min \{a \div c, a \div d, b \div c, b \div d\}, \max \{a \div c, a \div d, b \div c, b \div d\}]$, when 0 is not in $[c, d]$

Division by an interval containing zero is not defined under the basic interval arithmetic. Instead of working with an uncertain real $x$ we work with the two ends of the interval $[a, \mathrm{~b}]$ which contains $x$ such that $x$ lies between $a$ and $\mathrm{b}$, or could be one of them. Similarly a function $f$ when applied to $x$ is also uncertain. Instead, in interval arithmetic $f$ produces an interval $[a, \mathrm{~b}]$ which is all the possible values for $f(x)$ for all $x \in[a, b]$.

\subsubsection{Interval-Valued Function}

Let $a>0, b>0$ and consider the interval $[a, b]$. From a mathematical point of view, any real number can be represented on a line. Similarly, we can represent an interval by a function. If the interval is of the form $[a, b]$, the interval-valued function is taken as $h(p)=a^{(1-p)} b^{p}$ for $p \in[0,1]$.

Here we present some arithmetic operations on interval valued functions as follows: Let $A=\left[a_{l}, a_{u}\right]$ and $B=\left[b_{l}, b_{u}\right]$ be two interval numbers.

Addition: $A+B=\left[a_{l}, a_{u}\right]+\left[b_{l}, b_{u}\right]=\left[a_{l}+b_{l}, a_{u}+b_{u}\right]$ Provided $a_{l}+b_{l}>0$. The interval-valued function for the interval $A+B$ is given by $h(p)=a_{L}{ }^{(1-p)} a_{U}{ }^{p}$ where $a_{L}=a_{l}+b_{l}$ and $a_{U}=a_{u}+b_{u}$.

Subtraction: $A-B=\left[a_{l}, a_{u}\right]-\left[b_{l}, b_{u}\right]=\left[a_{l}-b_{l}, a_{u}-b_{u}\right]$. Provided $a_{l}-b_{l}>0$. The interval - valued function for the interval $A-B$ is given by $h(p)=b_{L}{ }^{(1-p)} b_{U}{ }^{p}$ where $b_{L}=a_{l}-b_{l}$ and $b_{U}=a_{u}-b_{u}$.

Scalar multiplication: $\alpha A=\alpha\left[a_{l}, a_{u}\right]=\left\{\begin{array}{l}{\left[\alpha a_{l}, \alpha a_{u}\right] \text { if } \alpha \geq 0} \\ {\left[\alpha a_{u}, \alpha a_{l}\right] \text { if } \alpha<0}\end{array}\right.$ provided $a_{l}>0$ and $a_{u}>0$. The interval valued function for interval $\alpha A$ is given by $h(p)=c_{L}{ }^{(1-p)} c_{U}{ }^{p}$ if $\alpha \geq 0$ and

$$
h(p)=-d_{L}^{(1-p)} d_{U}^{p} \text { if } \alpha<0 \text {, where } C_{L}=\alpha a_{l}, C_{U}=\alpha a_{u}, d_{U}=|\alpha| a_{u} \text { and } d_{L}=|\alpha| a_{l} \text {. }
$$

\subsubsection{Pontryagin's Maximum Principle}

Pontryagin's maximum principle is a powerful method for the computation of optimal controls, which has the crucial advantage that it does not require prior evaluation of the informal cost function. Let $b, c$ and $C$ are differentiable function in $t$ and $x$ with continuous derivatives, and that the stopping set $\mathrm{D}$ is a hyper plane, thus $D=\{y\}+\Sigma$ for some $y \in \mathbb{R}^{n}$ and some vector subspace $\Sigma$ of $\mathbb{R}^{n}$.

Define for $\lambda \in \mathbb{R}^{n}$ the Hamiltonian function as:

$$
\mathrm{H}(t, x, u, \lambda)=\lambda^{T} b(t, x, u)-c(t, x, u)
$$

Pontryagin's maximum principle states that if $\left(x_{t}, u_{t}\right) \leq \tau$ is optimal, then there exist adjoint Paths $\left(\lambda_{t}\right)_{t} \leq \tau$ in $\mathbb{R}^{n}$ and $\left(\mu_{t}\right)_{t} \leq \tau$ in $\mathbb{R}$ with the following properties for all $t \leq \tau$ $H\left(t, x_{t}, u, \lambda_{t}\right)+\mu_{t}$ has maximum value 0 , at the point $u=u_{t}$

$\dot{\lambda}_{t}{ }^{T}=-\lambda_{t}{ }^{T} \nabla b\left(t, \boldsymbol{x}_{t}, \boldsymbol{u}_{t}\right)-\nabla c\left(t, \boldsymbol{x}_{t}, \boldsymbol{u}_{t}\right)$

$\dot{\boldsymbol{u}}_{t}=\lambda_{t}{ }^{T} \nabla \dot{b}\left(t, \boldsymbol{x}_{t}, \boldsymbol{u}_{t}\right)-\dot{c}\left(t, \boldsymbol{x}_{t}, \boldsymbol{u}_{t}\right)$

$\dot{x}_{t}=\dot{b}\left(t, x_{t}, u_{t}\right)$

Moreover the following transversality conditions hold: $\left(x_{t}, u_{t}\right) \leq \tau$

$$
\left(\lambda_{\tau}{ }^{T}+\nabla C\left(\tau, x_{\tau}\right)\right) \sigma=0 \quad \text { or all } \sigma \in \Sigma \text { and, in the time-unconstrained case }
$$




$$
\mu_{\tau}+\dot{C}\left(\tau, x_{\tau}\right)=0
$$

Note that, in the time-unconstrained case, if $b, c$ and $C$ are time-independent functions, then all $t$

The Hamiltonian serves as a way of remembering the first four statements, which could be expressed alternatively as:

$$
\begin{array}{ll}
\text { i. } & \frac{\partial \mathrm{H}}{\partial u}=0 \\
\text { ii. } & -\frac{\partial \mathrm{H}}{\partial x}=\dot{\lambda} \\
\text { iii. } & -\frac{\partial \mathrm{H}}{\partial t}=\dot{\mu} \\
\text { iv. } & \frac{\partial \mathrm{H}}{\partial \lambda}=\dot{x}
\end{array}
$$

The condition $\frac{\partial \mathrm{H}}{\partial u}=0$ is not always correct. For example in cases where the set of actions is an interval and where the maximum is achieved at an endpoint

\section{MODEL FORMULATION AND ANALYSIS}

In section deals with the mathematical modeling of the prey-predator dynamics where there are two predators which compete for the same limited resources. In addition, the section deals with the stability analysis of the equilibrium points and the numerical simulation of the model.

\begin{tabular}{|l|l|}
\hline Parameter & Parameter Definition \\
\hline $\mathrm{R}$ & net economic rent \\
\hline$E_{i}, i=1,2,3$ & harvesting efforts \\
\hline$\delta$ & instantaneous annual rate of discount \\
\hline$q_{i}, i=1,2,3$ & catch ability coefficients \\
\hline$c_{i}, i=1,2,3$ & harvesting cost per unit effort \\
\hline
\end{tabular}

Table 3.1 Definition of some parameters

\subsection{Prey-Predator Model}

The ecological model is as follows. There is one prey and two predators, where the two predators are competes with each other for the use of common recourse i.e. food. But the two predators cannot eat each other (one is not eaten by the other). By assuming that the predator and competitor to the predator have alternative food in addition to prey population (but the competitor to the predator can't eat the prey population), then the model for one Prey and two Predator and harvesting on the both species is given by the following system of first order ordinary differential equations employing the following notation:

Let $\mathrm{N}_{1}$ denotes the size of the prey population, $\mathrm{N}_{2}$ denotes the size of the predator population and $\mathrm{N}_{3}$ denotes the size of the competitor to the predator population, lets assuming that there is demand for all species in the market so the harvesting of both species are carried out. Let prey, predator and competitor to the predator species are subjected to harvesting efforts (effort applied to the harvest the prey, predator and competitor species) $\mathrm{E}_{1}, \mathrm{E}_{2}$ and $\mathrm{E}_{3}$ respectively. Then the dynamics of the prey-predator is described by:

$$
\begin{aligned}
& \frac{d N_{1}}{d t}=r N_{1}-\alpha_{1}\left(N_{1}\right)^{2}-\beta_{1} N_{1} N_{2}-q_{1} \mathrm{E}_{1} N_{1} \\
& \frac{d N_{2}}{d t}=s N_{2}-\alpha_{2}\left(N_{2}\right)^{2}+\beta_{2} N_{1} N_{2}-\delta_{1} N_{2} N_{3}-q_{2} \mathrm{E}_{2} N_{2} \\
& \frac{d N_{3}}{d t}=\ell N_{3}-\alpha_{3}\left(N_{3}\right)^{2}-\beta_{3} N_{2} N_{3}-q_{3} \mathrm{E}_{3} N_{3}
\end{aligned}
$$

where $r, s$ and $\ell$ are natural growth rate of prey, predator and competitor to the predator species respectively. Whereas:

$\alpha_{1}$ is rate of decrease of the prey population due to inter species competition $\beta_{1}$ is rate of decrease of the prey population due to inhibition by the predator population, $\alpha_{2}$ is rate of decrease of the predator population due to inter species competition,

$\beta_{2}$ is rate of increase of the predator population due to successful attacks on the prey population, $\delta_{1}$ is rate of decrease of the predator population due to the competition with the third species(competitor), $\alpha_{3}$ is rate of decrease of the competitor population to the predator population due to inter species competition, 
$\beta_{3}$ is rate of decrease of the competitor population due to the competition with the third species(predator population). Where all the parameter values $\alpha_{1}, \alpha_{2}, \alpha_{3}, \beta_{1}, \beta_{2}, \beta_{3}$ and $\delta_{1}$ are non-negative real numbers.

It is assumed that the prey reproduction is influenced by the predator only while the predator reproduction is limited by the amount of prey caught. It is also assumed that the prey population grows exponentially with the rate $r$ in absence of predator and also predator population growth exponentially in the absence of prey by alternative food with a rate $s$. But the competitor to the predator can't change in the absence of the prey population. Where $q_{1}, q_{2}, q_{3}$ are the catch ability coefficients of three species and strictly positive. The catch-rate function: $q_{1} \mathrm{E}_{1} N_{1}, q_{2} \mathrm{E}_{2} N_{2}, q_{3} \mathrm{E}_{3} N_{3}$ are based on CPUE (catch-per unit-effort).

\subsection{Imprecise Prey - Predator Model}

By the construction of the prey-predator model the parameters such as prey population growth rate r, predator population growth rate $\mathrm{s}$, competitor to the predator growth rate $\ell$ and predation coefficients $\alpha_{1}, \alpha_{2}, \alpha_{3}, \beta_{1}, \beta_{2}, \beta_{3}$ and $\delta_{1}$ are positive in nature and are considered precise. Intuitively if any of the parameters are imprecise, furthermore when any parameter of the right hand side of equations (3.1) - (3.3) are interval number rather than a single value, then it is not so straight forward to convert equations to the standard form like (3.1), (3.2) and (3.3). For an imprecise coefficient we present the problem with an interval coefficient.

\subsubsection{Prey - Predator Model with Interval Coefficient}

Let $\hat{r}, \hat{s}, \hat{\ell}, \hat{\alpha}_{1}, \hat{\alpha}_{2}, \hat{\alpha}_{3}, \hat{\beta}_{1}, \hat{\beta}_{2}, \hat{\beta}_{3}$ and $\hat{\delta}_{1}$ be the interval counterparts of, $r, s, \ell, \alpha_{1}, \alpha_{2}, \alpha_{3}, \beta_{1}, \beta_{2}, \beta_{3}$ and $\delta_{1}$ respectively, then the prey-predator model with combined harvesting efforts $\mathrm{E}_{1}, \mathrm{E}_{2}$ and $\mathrm{E}_{3}$ can be written in the following form:

$$
\begin{aligned}
& \frac{d N_{1}}{d t}=\hat{r} N_{1}-\hat{\alpha}_{1}\left(N_{1}\right)^{2}-\hat{\beta}_{1} N_{1} N_{2}-q_{1} \mathrm{E}_{1} N_{1} \\
& \frac{d N_{2}}{d t}=\hat{s} N_{2}-\hat{\alpha}_{2}\left(N_{2}\right)^{2}+\hat{\beta}_{2} N_{1} N_{2}-\hat{\delta}_{1} N_{2} N_{3}-q_{2} \mathrm{E}_{2} N_{2} \\
& \frac{d N_{3}}{d t}=\hat{\ell} N_{3}-\hat{\alpha}_{3}\left(N_{3}\right)^{2}-\hat{\beta}_{3} N_{2} N_{3}-q_{3} \mathrm{E}_{3} N_{3}
\end{aligned}
$$

Where

$\hat{r} \in\left[r_{l}, r_{u}\right], \hat{s} \in\left[s_{l}, s_{u}\right], \hat{\ell} \in\left[\ell_{l}, \ell_{u}\right], \hat{\alpha}_{1} \in\left[\left(\alpha_{1}\right)_{l},\left(\alpha_{1}\right)_{u}\right], \hat{\alpha}_{2} \in\left[\left(\alpha_{2}\right)_{l},\left(\alpha_{2}\right)_{u}\right]$,

$\hat{\alpha}_{3} \in\left[\left(\alpha_{3}\right)_{l},\left(\alpha_{3}\right)_{u}\right], \hat{\beta}_{1} \in\left[\left(\beta_{1}\right)_{l},\left(\beta_{1}\right)_{u}\right], \hat{\beta}_{2} \in\left[\left(\beta_{2}\right)_{l},\left(\beta_{2}\right)_{u}\right], \hat{\beta}_{3} \in\left[\left(\beta_{3}\right)_{l},\left(\beta_{3}\right)_{u}\right]$ and

$\hat{\delta}_{1} \in\left[\left(\delta_{1}\right)_{l},\left(\delta_{1}\right)_{u}\right]$ With $r_{l}, s_{l}, \ell_{l},\left(\alpha_{1}\right)_{l},\left(\alpha_{2}\right)_{l},\left(\alpha_{3}\right)_{l},\left(\beta_{1}\right)_{l},\left(\beta_{2}\right)_{l},\left(\beta_{3}\right)_{l}$, and $\left(\delta_{1}\right)_{l}$ are all positive.

\subsubsection{Prey-Predator Model with Parametric Interval Valued Function Coefficient}

The parametric form of the equations (3.4), (3.5) and (3.6) are:

$$
\begin{aligned}
& \frac{d N_{1}(t ; p)}{d t}=\left(r_{l}\right)^{1-p}\left(r_{u}\right)^{p} N_{1}-\left(\left(\alpha_{1}\right)_{u}\right)^{1-p}\left(\left(\alpha_{1}\right)_{l}\right)^{p} N_{1}{ }^{2}-\left(\left(\beta_{1}\right)_{u}\right)^{1-p}\left(\left(\beta_{1}\right)_{l}\right)^{p} N_{1} N_{2}-q_{1} \mathrm{E}_{1} N_{1} \\
& \frac{d N_{2}(t ; p)}{d t}=\left(s_{l}\right)^{1-p}\left(s_{u}\right)^{p} N_{2}-\left(\left(\alpha_{2}\right)_{u}\right)^{1-p}\left(\left(\alpha_{2}\right)_{l}\right)^{p} N_{2}{ }^{2}+\left(\left(\beta_{2}\right)_{l}\right)^{1-p}\left(\left(\beta_{2}\right)_{u}\right)^{p} N_{1} N_{2} \\
& \quad-\left(\left(\delta_{1}\right)_{u}\right)^{1-p}\left(\left(\delta_{1}\right)_{l}\right)^{p} N_{2} N_{3}-q_{2} \mathrm{E}_{2} N_{2} \\
& \frac{d N_{3}(t ; p)}{d t}=\left(\ell_{l}\right)^{1-p}\left(\ell_{u}\right)^{p} N_{3}-\left(\left(\alpha_{3}\right)_{u}\right)^{1-p}\left(\left(\alpha_{3}\right)_{l}\right)^{p} N_{3}{ }^{2}-\left(\left(\beta_{3}\right)_{u}\right)^{1-p}\left(\left(\beta_{3}\right)_{l}\right)^{p} N_{2} N_{3}-q_{3} \mathrm{E}_{3} N_{3}
\end{aligned}
$$

Theorem 1: The differential equations with interval valued coefficient

$$
\begin{aligned}
& \frac{d N_{1}}{d t}=\hat{r}_{0} N_{1}-\hat{\alpha}_{0}\left(N_{1}\right)^{2}-\hat{\beta}_{0} N_{1} N_{2}-q_{1} \mathrm{E}_{1} N_{1} \\
& \frac{d N_{2}}{d t}=\hat{s}_{0} N_{2}-\hat{\tau}_{0}\left(N_{2}\right)^{2}+\hat{\gamma}_{0} N_{1} N_{2}-\hat{\delta}_{0} N_{2} N_{3}-q_{2} \mathrm{E}_{2} N_{2} \\
& \frac{d N_{3}}{d t}=\hat{\ell}_{0} N_{3}-\hat{\rho}_{0}\left(N_{3}\right)^{2}-\hat{\psi}_{0} N_{2} N_{3}-q_{3} \mathrm{E}_{3} N_{3}
\end{aligned}
$$

Where $\hat{r}_{0} \in\left[r_{l}, r_{u}\right], \hat{s}_{0} \in\left[s_{l}, s_{u}\right], \hat{\ell}_{0} \in\left[\ell_{l}, \ell_{u}\right], \hat{\alpha}_{0} \in\left[\alpha_{l}, \alpha_{u}\right], \hat{\beta}_{0} \in\left[\beta_{l}, \beta_{u}\right]$, $\hat{\tau}_{0} \in\left[\tau_{l}, \tau_{u}\right], \hat{\gamma}_{0} \in\left[\gamma_{l}, \gamma_{u}\right], \hat{\delta}_{0} \in\left[\delta_{l}, \delta_{u}\right], \hat{\rho}_{0} \in\left[\rho_{l}, \rho_{u}\right]$ and $\hat{\psi}_{0} \in\left[\psi_{l}, \psi_{u}\right]$

Also $r_{l}, \ell_{l}, s_{l}, \alpha_{l}, \beta_{l}, \tau_{l}, \gamma_{l}, \rho_{l}, \delta_{l}$ and $\psi_{l}$ (are all $>0$ ) are provided interval valued functional form of coefficient by the differential equations:

$$
\begin{aligned}
& \frac{d N_{1}(t ; p)}{d t}=\left(r_{l}\right)^{1-p}\left(r_{u}\right)^{p} N_{1}-\left(\alpha_{u}\right)^{1-p}\left(\alpha_{l}\right)^{p} N_{1}{ }^{2}-\left(\beta_{u}\right)^{1-p}\left(\beta_{l}\right)^{p} N_{1} N_{2}-q_{1} \mathrm{E}_{1} N_{1} \\
& \frac{d N_{2}(t ; p)}{d t}=\left(s_{l}\right)^{1-p}\left(s_{u}\right)^{p} N_{2}-\left(\tau_{u}\right)^{1-p}\left(\tau_{l}\right)^{p} N_{2}{ }^{2}+\left(\gamma_{l}\right)^{1-p}\left(\gamma_{u}\right)^{p} N_{1} N_{2} \\
& -\left(\delta_{u}\right)^{1-p}\left(\delta_{l}\right)^{p} N_{2} N_{3}-q_{2} \mathrm{E}_{2} \mathrm{~N}_{2} \\
& \frac{d N_{3}(t ; p)}{d t}=\left(\ell_{l}\right)^{1-p}\left(\ell_{u}\right)^{p} N_{3}-\left(\rho_{u}\right)^{1-p}\left(\rho_{l}\right)^{p} N_{3}{ }^{2}-\left(\psi_{u}\right)^{1-p}\left(\psi_{l}\right)^{p} N_{2} N_{3}-q_{3} \mathrm{E}_{3} N_{3}
\end{aligned}
$$

for $p \in[0,1]$.

Proof: Replacing in place of $\hat{r}_{0}, \hat{s}_{0}, \hat{\ell}_{0}, \hat{\alpha}_{0}, \hat{\beta}_{0}, \hat{\tau}_{0}, \hat{\gamma}_{0}, \hat{\delta}_{0}, \hat{\rho}_{0}$ and $\hat{\psi}_{0}$ by $\left[r_{l}, r_{u}\right],\left[s_{l}, s_{u}\right],\left[\ell_{l}, \ell_{u}\right],\left[\alpha_{l}, \alpha_{u}\right]$, $\left[\beta_{l}, \beta_{u}\right],\left[\tau_{l}, \tau_{u}\right],\left[\gamma_{l}, \gamma_{u}\right],\left[\delta_{l}, \delta_{u}\right],\left[\rho_{l}, \rho_{u}\right]$ and $\left[\psi_{l}, \psi_{u}\right]$ respectively, then equation (3.10), (3.11) and (3.12) will be come:

$\frac{d N_{1}}{d t}=\left[r_{l}, r_{u}\right] N_{1}-\left[\alpha_{l}, \alpha_{u}\right]\left(N_{1}\right)^{2}-\left[\beta_{l}, \beta_{u}\right] N_{1} N_{2}-q_{1} \mathrm{E}_{1} N_{1}$ 
$\frac{d N_{2}}{d t}=\left[s_{l}, s_{u}\right] N_{2}-\left[\tau_{l}, \tau_{u}\right]\left(N_{2}\right)^{2}+\left[\gamma_{l}, \gamma_{u}\right] N_{1} N_{2}-\left[\delta_{l}, \delta_{u}\right] N_{2} N_{3}-q_{2} \mathrm{E}_{2} N_{2}$

$\frac{d N_{3}}{d t}=\left[\ell_{l}, \ell_{u}\right] N_{3}-\left[\rho_{l}, \rho_{u}\right]\left(N_{3}\right)^{2}-\left[\psi_{l}, \psi_{u}\right] N_{2} N_{3}-q_{3} \mathrm{E}_{3} N_{3}$

Let $r_{1}^{\prime} \in\left[r_{l}, r_{u}\right], s_{1}^{\prime} \in\left[s_{l}, s\right], \ell_{1}^{\prime} \in\left[\ell_{l}, \ell_{u}\right], \alpha_{1}^{\prime} \in\left[\alpha_{l}, \alpha_{u}\right], \tau_{1}^{\prime} \in\left[\tau_{l}, \tau_{u}\right], \rho_{1}^{\prime} \in\left[\rho_{l}, \rho_{u}\right], \beta_{1}^{\prime} \in\left[\beta_{l}, \beta_{u}\right], \gamma_{1}^{\prime} \in\left[\gamma_{l}, \gamma_{u}\right]$, $\delta_{1}^{\prime} \in\left[\delta_{l}, \delta_{u}\right]$ and $\psi_{1}^{\prime} \in\left[\psi_{l}, \psi_{u}\right]$ respectively. Following the interval arithmetic operation and properties, equations (3.16), (3.17) and (3.18) reduces to:

$\begin{aligned} \frac{d \mathrm{~N}_{1}}{d t} & =r_{1}^{\prime} \mathrm{N}_{1}-\alpha_{1}^{\prime} \mathrm{N}_{1}^{2}-\beta_{1}^{\prime} \mathrm{N}_{1} \mathrm{~N}_{2}-q_{1} \mathrm{E}_{1} \mathrm{~N}_{1} \\ \frac{d \mathrm{~N}_{2}}{d t} & =s_{1}^{\prime} \mathrm{N}_{2}-\tau_{1}^{\prime} \mathrm{N}_{2}^{2}+\gamma_{1}^{\prime} \mathrm{N}_{1} \mathrm{~N}_{2}-\delta_{1}^{\prime} \mathrm{N}_{2} \mathrm{~N}_{3}-q_{2} \mathrm{E}_{2} \mathrm{~N}_{2} \\ \frac{d \mathrm{~N}_{3}}{d t} & =\ell_{1}^{\prime} \mathrm{N}_{3}-\rho_{1}^{\prime} \mathrm{N}_{3}{ }^{2}-\psi_{1}^{\prime} \mathrm{N}_{2} \mathrm{~N}_{3}-q_{3} \mathrm{E}_{3} \mathrm{~N}_{3}\end{aligned}$

For fixed $n$, let us consider the interval-valued function $h_{n}{ }^{(p)}=a_{n}{ }^{(1-p)} b_{n}{ }^{(p)}$ for $p \in[0,1]$ and interval $\alpha_{n} \in\left[a_{n}, b_{n}\right]$. Since $h_{n}{ }^{(p)}$ is a strictly increasing and continuous functions, then the above equation reduces to:

$\frac{d \mathrm{~N}_{1}}{d t}=r_{1}^{\prime \prime} \mathrm{N}_{1}-\alpha_{1}^{\prime \prime}\left(\mathrm{N}_{1}\right)^{2}-\beta_{1}^{\prime \prime} \mathrm{N}_{1} \mathrm{~N}_{2}-q_{1} \mathrm{E}_{1} \mathrm{~N}_{1}$

$\frac{d \mathrm{~N}_{2}}{d t}=s_{1}^{\prime \prime} \mathrm{N}_{2}-\tau_{1}^{\prime \prime}\left(\mathrm{N}_{2}\right)^{2}+\gamma_{1}^{\prime \prime} \mathrm{N}_{1} \mathrm{~N}_{2}-\delta_{1}^{\prime \prime} \mathrm{N}_{2} \mathrm{~N}_{3}-q_{2} \mathrm{E}_{2} \mathrm{~N}_{2}$

$\frac{d \mathrm{~N}_{3}}{d t}=\ell_{1}^{\prime \prime} \mathrm{N}_{3}-\rho_{1}^{\prime \prime}\left(\mathrm{N}_{3}\right)^{2}-\psi_{1}^{\prime \prime} \mathrm{N}_{2} \mathrm{~N}_{3}-q_{3} \mathrm{E}_{3} \mathrm{~N}_{3}$

Where

$r_{1}^{\prime \prime} \in\left(r_{l}\right)^{1-p}\left(r_{u}\right)^{p}, s_{1}^{\prime \prime} \in\left(s_{l}\right)^{1-p}\left(s_{u}\right)^{p}, \ell_{1}^{\prime \prime} \in\left(\ell_{l}\right)^{1-p}\left(\ell_{u}\right)^{p}, \alpha_{1}^{\prime \prime} \in\left(\alpha_{u}\right)^{1-p}\left(\alpha_{l}\right)^{p}, \tau_{1}^{\prime \prime} \in\left(\tau_{u}\right)^{1-p}\left(\tau_{l}\right)^{p}, \rho_{1}^{\prime \prime} \in$ $\left(\rho_{u}\right)^{1-p}\left(\rho_{l}\right)^{p}, \beta_{1}^{\prime \prime} \in\left(\beta_{u}\right)^{1-p}\left(\beta_{l}\right)^{p}, \gamma_{1}^{\prime \prime} \in\left(\gamma_{l}\right)^{1-p}\left(\gamma_{u}\right)^{p}, \delta_{1}^{\prime \prime} \in\left(\delta_{u}\right)^{1-p}\left(\delta_{l}\right)^{p}$,

$\psi_{1}^{\prime \prime} \in\left(\psi_{u}\right)^{1-p}\left(\psi_{l}\right)^{p}$ and $p \in[0,1]$.

Therefore the parametric form of the differential equations (3.10) - (3.12) is given by:

$\frac{d \mathrm{~N}_{1}}{d t}=\left(r_{l}\right)^{1-p}\left(r_{u}\right)^{p} \mathrm{~N}_{1}-\left(\alpha_{u}\right)^{1-p}\left(\alpha_{l}\right)^{p} \mathrm{~N}_{1}{ }^{2}-\left(\beta_{u}\right)^{1-p}\left(\beta_{l}\right)^{p} \mathrm{~N}_{1} \mathrm{~N}_{2}-q_{1} \mathrm{E}_{1} \mathrm{~N}_{1}$

$\frac{d \mathrm{~N}_{2}}{d t}=\left(s_{l}\right)^{1-p}\left(s_{u}\right)^{p} \mathrm{~N}_{2}-\left(\tau_{u}\right)^{1-p}\left(\tau_{l}\right)^{p} \mathrm{~N}_{2}{ }^{2}+\left(\gamma_{l}\right)^{1-p}\left(\gamma_{u}\right)^{p} \mathrm{~N}_{1} \mathrm{~N}_{2}-\left(\delta_{u}\right)^{1-p}\left(\delta_{l}\right)^{p} \mathrm{~N}_{2} \mathrm{~N}_{3}-q_{2} \mathrm{E}_{2} \mathrm{~N}_{2}$

$\frac{d \mathrm{~N}_{3}}{d t}=\left(\ell_{l}\right)^{1-p}\left(\ell_{u}\right)^{p} \mathrm{~N}_{3}-\left(\rho_{u}\right)^{1-p}\left(\rho_{l}\right)^{p} \mathrm{~N}_{3}{ }^{2}-\left(\psi_{u}\right)^{1-p}\left(\psi_{l}\right)^{p} \mathrm{~N}_{2} \mathrm{~N}_{3}-q_{3} \mathrm{E}_{3} \mathrm{~N}_{3}$ for $p \in[0,1]$.

\subsection{Dynamic Behavior of the Harvesting Model}

2.3.1 Equilibrium States of Prey-Predator Model with Parametric Interval Coefficient

The system under investigation has eight equilibrium states given by:

$$
\frac{d N_{i}(t, p)}{d t}=0, i=1,2,3
$$

The possible equilibrium points of the systems are:

I. The extinct state:

$$
\overline{\mathrm{N}}_{1}=0, \overline{\mathrm{N}}_{2}=0 \text { and } \overline{\mathrm{N}}_{3}=0
$$

II. The state in which both the predator and competitor to the predator washed out and prey survive: That is:

$\overline{\mathrm{N}}_{2}=\overline{\mathrm{N}}_{3}=0$ and $\overline{\mathrm{N}}_{1}=\frac{a-q_{1} \mathrm{E}_{1}}{b}$, where $a=\left(r_{l}\right)^{1-p}\left(r_{u}\right)^{p}$ and $b=\left(\left(\alpha_{1}\right)_{u}\right)^{1-p}\left(\left(\alpha_{1}\right)_{l}\right)^{p}$

$$
\left(\frac{a-q_{1} E_{1}}{b}, 0,0\right)
$$

III. The state in which only the predator survives and the prey and competitor to the predator are washed out:

That is:

$\overline{\mathrm{N}}_{1}=\overline{\mathrm{N}}_{3}=0$ and $\overline{\mathrm{N}}_{2}=\frac{d-q_{2} \mathrm{E}_{2}}{e}$ where $d=\left(s_{l}\right)^{1-p}\left(s_{u}\right)^{p}$ and $e=\left(\left(\alpha_{2}\right)_{u}\right)^{1-p}\left(\left(\alpha_{2}\right)_{l}\right)^{p}$
\[ \left(0, \frac{d-q_{2} \mathrm{E}_{2}}{e}, 0\right) \]

IV. The state in which both the prey and the predators washed out and competitor to the predator survive:

That is:

$\overline{\mathrm{N}}_{1}=\overline{\mathrm{N}}_{2}=0$ and $\overline{\mathrm{N}}_{3}=\frac{h-q_{3} \mathrm{E}_{3}}{k}$ where $h=\left(\ell_{l}\right)^{1-p}\left(\ell_{u}\right)^{p}$ and $k=\left(\left(\alpha_{3}\right)_{u}\right)^{1-p}\left(\left(\alpha_{3}\right)_{l}\right)^{p}$

$$
\left(0,0, \frac{h-q_{3} E_{3}}{k}\right)
$$

V. The state in which both the prey and the predators stay alive and competitor to the predator vanishes: That is:

$\overline{\mathrm{N}}_{3}=0$

$\left(r_{l}\right)^{1-p}\left(r_{u}\right)^{p} \overline{\mathrm{N}}_{1}-\left(\left(\alpha_{1}\right)_{u}\right)^{1-p}\left(\left(\alpha_{1}\right)_{l}\right)^{p} \overline{\mathrm{N}}_{1}^{2}-\left(\left(\beta_{1}\right)_{u}\right)^{1-p}\left(\left(\beta_{1}\right)_{l}\right)^{p} \overline{\mathrm{N}}_{1} \overline{\mathrm{N}}_{2}-q_{1} \mathrm{E}_{1} \overline{\mathrm{N}}_{1}=0$

And 
$\left(s_{l}\right)^{1-p}\left(s_{u}\right)^{p} \overline{\mathrm{N}}_{2}-\left(\left(\alpha_{2}\right)_{u}\right)^{1-p}\left(\left(\alpha_{2}\right)_{l}\right)^{p} \overline{\mathrm{N}}_{2}{ }^{2}+\left(\left(\beta_{2}\right)_{l}\right)^{1-p}\left(\left(\beta_{1}\right)_{u}\right)^{p} \overline{\mathrm{N}}_{1} \overline{\mathrm{N}}_{2}-q_{2} \mathrm{E}_{2} \overline{\mathrm{N}}_{2}=0$

Solving for $\overline{\mathrm{N}}_{1}$ and $\overline{\mathrm{N}}_{2}$ from the $2^{\text {nd }}$ and $3^{\text {rd }}$ equations that given in equation (3.30) yields:

$$
\overline{\mathrm{N}}_{1}=\frac{e\left(a-q_{1} \mathrm{E}_{1}\right)+c\left(d+q_{2} \mathrm{E}_{2}\right)}{b e+c f} \text { and } \overline{\mathrm{N}}_{2}=\frac{f\left(a-q_{1} \mathrm{E}_{1}\right)-b\left(d+q_{2} \mathrm{E}_{2}\right)}{b e+c f}
$$

where $a=\left(r_{l}\right)^{1-p}\left(r_{u}\right)^{p}, b=\left(\left(\alpha_{1}\right)_{u}\right)^{1-p}\left(\left(\alpha_{1}\right)_{l}\right)^{p}, c=\left(\left(\beta_{1}\right)_{u}\right)^{1-p}\left(\left(\beta_{1}\right)_{l}\right)^{p}$,

$$
d=\left(s_{l}\right)^{1-p}\left(s_{u}\right)^{p}, e=\left(\left(\alpha_{2}\right)_{u}\right)^{1-p}\left(\left(\alpha_{2}\right)_{l}\right)^{p} \text { and } f=\left(\left(\beta_{2}\right)_{u}\right)^{1-p}\left(\left(\beta_{2}\right)_{l}\right)^{p}
$$

Also assuming that $a-q_{1} \mathrm{E}_{1}>0$, then these equilibrium states' exist only when:

$$
f\left(a-q_{1} \mathrm{E}_{1}\right)>b\left(d+q_{2} \mathrm{E}_{2}\right)
$$

\section{The state in which both prey and competitor to the predator exist and predator extinct:}

That is:

$$
\overline{\mathrm{N}_{2}}=0, \overline{\mathrm{N}_{1}}=\frac{a-q_{1} \mathrm{E}_{1}}{b} \text { and } \overline{\mathrm{N}}_{3}=\frac{h-q_{3} \mathrm{E}_{3}}{k}
$$

where $a=\left(r_{l}\right)^{1-p}\left(r_{u}\right)^{p}, b=\left(\left(\alpha_{1}\right)_{u}\right)^{1-p}\left(\left(\alpha_{1}\right)_{l}\right)^{p}$,

$$
h=\left(\ell_{l}\right)^{1-p}\left(\ell_{u}\right)^{p} \text { and } k=\left(\left(\alpha_{3}\right)_{u}\right)^{1-p}\left(\left(\alpha_{3}\right)_{l}\right)^{p}
$$

The equilibrium state exists when: $a-q_{1} \mathrm{E}_{1}>0$ and $h-q_{3} \mathrm{E}_{3}>0$

VII. The state in which both Predator and Competitor to the Predator exist and Prey washed out: That is:

$\overline{N_{1}}=0$,

$\left(s_{l}\right)^{1-p}\left(s_{u}\right)^{p} \overline{\mathrm{N}_{2}}-\left(\left(\alpha_{2}\right)_{u}\right)^{1-p}\left(\left(\alpha_{2}\right)_{l}\right)^{p}\left(\overline{\mathrm{N}_{2}}\right)^{2}-\left(\left(\delta_{1}\right)_{u}\right)^{1-p}\left(\left(\delta_{1}\right)_{l}\right)^{p} \overline{\mathrm{N}_{2} \mathrm{~N}_{3}}-q_{2} \mathrm{E}_{2} \overline{\mathrm{N}_{2}}=0$ and

$\left(\ell_{l}\right)^{1-p}\left(\ell_{u}\right)^{p} \overline{\mathrm{N}_{3}}-\left(\left(\alpha_{3}\right)_{u}\right)^{1-p}\left(\left(\alpha_{3}\right)_{l}\right)^{p}\left(\overline{\mathrm{N}_{3}}\right)^{2}-\left(\left(\beta_{3}\right)_{u}\right)^{1-p}\left(\left(\beta_{3}\right)_{l}\right)^{p} \overline{\mathrm{N}_{2} \mathrm{~N}_{3}}-q_{3} \mathrm{E}_{3} \overline{\mathrm{N}_{3}}=0$

Solving for $\bar{N}_{2}$ and $\bar{N}_{3}$ from the $2^{\text {nd }}$ and $3^{\text {rd }}$ equations that given in equation (3.32) yields:

$$
\overline{\mathrm{N}}_{2}=\frac{k\left(d-q_{2} \mathrm{E}_{2}\right)-g\left(h-q_{3} \mathrm{E}_{3}\right)}{e k-m g} \text { and } \overline{\mathrm{N}}_{2}=\frac{e\left(h-q_{2} \mathrm{E}_{2}\right)-m\left(d-q_{3} \mathrm{E}_{3}\right)}{e k-m g}
$$

where $d=\left(s_{l}\right)^{1-p}\left(s_{u}\right)^{p}, e=\left(\left(\alpha_{2}\right)_{u}\right)^{1-p}\left(\left(\alpha_{2}\right)_{l}\right)^{p}, g=\left(\left(\delta_{1}\right)_{u}\right)^{1-p}\left(\left(\delta_{1}\right)_{l}\right)^{p}$,

$$
h=\left(\ell_{l}\right)^{1-p}\left(\ell_{u}\right)^{p}, k=\left(\left(\alpha_{3}\right)_{u}\right)^{1-p}\left(\left(\alpha_{3}\right)_{l}\right)^{p} \text { and } m=\left(\left(\beta_{3}\right)_{u}\right)^{1-p}\left(\left(\beta_{3}\right)_{l}\right)^{p}
$$

Assuming that $d-q_{2} \mathrm{E}_{2}>0, h-q_{3} \mathrm{E}_{3}>0, h-q_{2} \mathrm{E}_{2}$ and $d-q_{3} \mathrm{E}_{3}>0$, then these equilibrium states' exist only when:

VIII. Co-existence State

$$
k\left(d-q_{2} \mathrm{E}_{2}\right)>g\left(h-q_{3} \mathrm{E}_{3}\right), e\left(h-q_{2} \mathrm{E}_{2}\right)>m\left(d-q_{3} \mathrm{E}_{3}\right) \text { and } e k>m g
$$

$$
\begin{aligned}
& \bar{N}_{1}=\frac{\left(a-q_{1} E_{1}\right)(e k-g m)-k c\left(d-q_{2} E_{2}\right)+c g\left(h-q_{3} E_{3}\right)}{b(e k-g m)+c f k} \\
& \bar{N}_{2}=\frac{f k\left(a-q_{1} E_{1}\right)+b k\left(d-q_{2} E_{2}\right)-g b\left(h-q_{3} E_{3}\right)}{b(e k-g m)+c f k}
\end{aligned}
$$

and

$$
\bar{N}_{3}=\frac{\left(h-q_{3} E_{3}\right)(b e+c f)-f m\left(a-q_{1} E_{1}\right)-b m\left(d-q_{2} E_{2}\right)}{b(e k-g m)+c f k}
$$

where $a=\left(r_{l}\right)^{1-p}\left(r_{u}\right)^{p}, b=\left(\left(\alpha_{1}\right)_{u}\right)^{1-p}\left(\left(\alpha_{1}\right)_{l}\right)^{p}, c=\left(\left(\beta_{1}\right)_{l}\right)^{1-p}\left(\left(\beta_{1}\right)_{u}\right)^{p}$,

$g=\left(\left(\delta_{1}\right)_{u}\right)^{1-p}\left(\left(\delta_{1}\right)_{l}\right)^{p}, d=\left(s_{l}\right)^{1-p}\left(s_{u}\right)^{p}, e=\left(\left(\alpha_{2}\right)_{u}\right)^{1-p}\left(\left(\alpha_{2}\right)_{l}\right)^{p}, f=\left(\left(\beta_{2}\right)_{l}\right)^{1-p}\left(\left(\beta_{2}\right)_{u}\right)^{p}$,

$h=\left(\ell_{l}\right)^{1-p}\left(\ell_{u}\right)^{p}, k=\left(\left(\alpha_{3}\right)_{u}\right)^{1-p}\left(\left(\alpha_{3}\right)_{l}\right)^{p}$ and $m=\left(\left(\beta_{3}\right)_{l}\right)^{1-p}\left(\left(\beta_{3}\right)_{u}\right)^{p}$

Assuming that $d-q_{2} \mathrm{E}_{2}>0, h-q_{3} \mathrm{E}_{3}>0$ and $a-q_{1} \mathrm{E}_{1}>0$, then these equilibrium states' exists only when:

$c g\left(h-q_{3} E_{3}\right)+\left(a-q_{1} \mathrm{E}_{1}\right)(e k-g m)>k c\left(d-q_{2} E_{2}\right)$

$f k\left(a-q_{1} E_{1}\right)+b k\left(d-q_{2} E_{2}\right)>g b\left(h-q_{3} \mathrm{E}_{3}\right)$

\subsubsection{Stability Analysis}

To investigate the stability of the equilibrium states we consider small perturbations $\mathrm{u}_{1}, \mathrm{u}_{2}$ and $\mathrm{u}_{3}$ in $\mathrm{N}_{1}, \mathrm{~N}_{2}$ and $\mathrm{N}_{3}$ over $\overline{\mathrm{N}}_{1}, \overline{\mathrm{N}}_{2}$ and $\overline{\mathrm{N}}_{3}$ respectively, so that

$$
\mathrm{N}_{1}=\overline{\mathrm{N}}_{1}+u_{1}, \mathrm{~N}_{2}=\overline{\mathrm{N}}_{2}+u_{2}, \mathrm{~N}_{3}=\overline{\mathrm{N}}_{3}+u_{3}
$$

By substituting (3.33) in to equations (3.1) - (3.3) and neglecting second and higher order terms of the Perturbations $u_{1}, u_{2}$ and $u_{3}$ we get the equations of the perturbed state:

Where $\mathbb{U}=\left(u_{1}, u_{2}, u_{3}\right)$ and

$$
\frac{d \mathbb{U}}{d t}=\mathbb{A} \mathbb{U}
$$




$$
\mathbb{A}=\left[\begin{array}{ccc}
a-2 b \overline{\mathrm{N}}_{1}-c \overline{\mathrm{N}}_{2}-q_{1} \mathrm{E}_{1} & -c \overline{\mathrm{N}}_{1} & 0 \\
f \overline{\mathrm{N}}_{2} & d-2 e \overline{\mathrm{N}}_{2}+f \overline{\mathrm{N}}_{1}-g \overline{\mathrm{N}}_{3}-q_{2} \mathrm{E}_{2} & -g \overline{\mathrm{N}}_{2} \\
0 & -m \overline{\mathrm{N}}_{3} & h-2 k \overline{\mathrm{N}}_{3}-m \overline{\mathrm{N}}_{2}-q_{3} \mathrm{E}_{3}
\end{array}\right]
$$

The characteristic equation for the system is:

$$
d[\mathbb{A}-\lambda \mathrm{I}]=0
$$

The equilibrium state is stable, if three roots of the equation (3.36) have negative real parts.

Solving for $a, \mathrm{~d}$ and $\mathrm{h}$ from the equation (3.1) - (3.3) respectively and substituting in to the equation (3.35) we obtain the variational matrix:

$$
\mathbb{A}=\left[\begin{array}{ccc}
-b \overline{\mathrm{N}}_{1} & -c \overline{\mathrm{N}}_{1} & 0 \\
f \overline{\mathrm{N}}_{2} & -e \overline{\mathrm{N}}_{2} & -g \overline{\mathrm{N}}_{2} \\
0 & -m \overline{\mathrm{N}}_{3} & -k \overline{\mathrm{N}}_{3}
\end{array}\right]
$$

Where $a=b \overline{\mathrm{N}}_{1}+c \overline{\mathrm{N}}_{2}+q_{1} \mathrm{E}_{1}, d=e \overline{\mathrm{N}}_{2}-f \overline{\mathrm{N}}_{1}+g \overline{\mathrm{N}}_{3}+q_{2} \mathrm{E}_{2}$ and $h=k \overline{\mathrm{N}}_{3}+m \overline{\mathrm{N}}_{2}+q_{3} \mathrm{E}_{3}$

\subsubsection{Local Stability Analysis}

The local and global stability of the equilibrium states I, II, III and IV are found to be unstable. But the reaming is stable. We restricted our study to the equilibrium states V, VI, VII and VIII.

i. Stability of the Equilibrium State $\left(\overline{\mathbf{N}}_{1}, \overline{\mathbf{N}}_{2}, \mathbf{0}\right)$ :

The variational matrix at the trivial equilibrium point will become:

$$
\mathbb{A}=\left[\begin{array}{ccc}
a-2 b \overline{\mathrm{N}}_{1}-c \overline{\mathrm{N}}_{2}-q_{1} \mathrm{E}_{1} & -c \overline{\mathrm{N}}_{1} & 0 \\
f \overline{\mathrm{N}}_{2} & d-2 e \overline{\mathrm{N}}_{2}+f \overline{\mathrm{N}}_{1}-q_{2} \mathrm{E}_{2} & -g \overline{\mathrm{N}}_{2} \\
0 & 0 & h-m \overline{\mathrm{N}}_{2}-q_{3} \mathrm{E}_{3}
\end{array}\right]
$$

The Characteristic equation of the above variational matrix is given by:

$$
d[\mathbb{A}-\lambda \mathrm{I}]=0
$$

One of the Eigen values of variational matrix $\mathrm{A}$ is $\lambda=\left(h-q_{3} \mathrm{E}_{3}\right)-m \overline{\mathrm{N}}_{2}$ and the other two are obtained from the quadratic equation:

$$
\lambda^{2}+\left(b \overline{\mathrm{N}}_{1}+e \overline{\mathrm{N}}_{2}\right) \lambda+(b e+c f) \overline{\mathrm{N}}_{1} \overline{\mathrm{N}}_{2}=0
$$

In (3.39), the sum of the roots, $-\left(b \overline{\mathrm{N}}_{1}+e \overline{\mathrm{N}}_{2}\right)$, is negative and the product of the roots,

$(b e+c f) \overline{\mathrm{N}}_{1} \overline{\mathrm{N}}_{2}$, is positive. Therefore the roots of (3.39) are real and negative or complex conjugates having negative real parts. Thus the equilibrium point is asymptotically stable when

$\left(h-q_{3} \mathrm{E}_{3}\right)<m \overline{\mathrm{N}}_{2}$.

\section{ii. Stability of the Equilibrium State at $\left(\overline{\mathbf{N}}_{1}, \mathbf{0}, \overline{\mathbf{N}}_{3}\right)$ :}

The variational matrix at the trivial equilibrium point (state) is:

$$
\mathbb{A}=\left[\begin{array}{ccc}
a-2 b \overline{\mathrm{N}}_{1}-q_{1} \mathrm{E}_{1} & -c \overline{\mathrm{N}}_{1} & 0 \\
0 & d+f \overline{\mathrm{N}}_{1}-g \overline{\mathrm{N}}_{3}-q_{2} \mathrm{E}_{2} & 0 \\
0 & -m \overline{\mathrm{N}}_{3} & h-2 k \overline{\mathrm{N}}_{3}-q_{3} \mathrm{E}_{3}
\end{array}\right]
$$

The roots of the corresponding characteristic equations are:

$$
\lambda_{1}=-\left(a-q_{1} \mathrm{E}_{1}\right), \lambda_{2}=d+\frac{f}{b}\left(a-q_{1} \mathrm{E}_{1}\right)-\frac{g}{k}\left(h-q_{3} \mathrm{E}_{3}\right) \text { and } \lambda_{3}=-\left(h-q_{3} \mathrm{E}_{3}\right)
$$

The equilibrium point is asymptotically stable when $d+\frac{f}{b}\left(a-q_{1} \mathrm{E}_{1}\right)<\frac{g}{k}\left(h-q_{3} \mathrm{E}_{3}\right)$.

iii. Stability of the equilibrium state at $\left(\mathbf{0}, \overline{\mathbf{N}}_{2}, \overline{\mathbf{N}}_{3}\right)$ :

The variational matrix at the trivial equilibrium point (state) is:

$$
\mathbb{A}=\left[\begin{array}{ccc}
a-c \overline{\mathrm{N}}_{2}-q_{1} \mathrm{E}_{1} & 0 & 0 \\
f \overline{\mathrm{N}}_{2} & d-2 e \overline{\mathrm{N}}_{2}-g \overline{\mathrm{N}}_{3}-q_{2} \mathrm{E}_{2} & -g \overline{\mathrm{N}}_{2} \\
0 & -m \overline{\mathrm{N}}_{3} & h-2 k \overline{\mathrm{N}}_{3}-m \overline{\mathrm{N}}_{2}-q_{3} \mathrm{E}_{3}
\end{array}\right]
$$

One of the Eigen values of variational matrix $\mathbb{A}$ is $\lambda_{1}=\left(a-q_{1} E_{1}\right)-c \bar{N}_{2}$ and the other two are obtained from the quadratic equation:

$$
\lambda^{2}+\left(e \bar{N}_{2}+k \bar{N}_{3}\right) \lambda+(e k-g m) \bar{N}_{2} \bar{N}_{3}=0
$$

In (3.41), the sum of the roots $-\left(e \bar{N}_{2}+k \bar{N}_{3}\right)$ is negative and the product of the roots

$(e k-g m) \bar{N}_{2} \bar{N}_{3}$ is positive. Therefore the roots of (3.41) are real and negative or complex conjugates having negative real parts. Thus the state will be asymptotically stable when

$$
\left(a-q_{1} E_{1}\right)<c \bar{N}_{2} \text {. }
$$

\section{iv. Stability of the positive interior equilibrium point}

The variational matrix at the positive interior equilibrium point is: 


$$
\begin{gathered}
\mathbb{A}=\left[\begin{array}{ccc}
-b \overline{\mathrm{N}}_{1} & -c \overline{\mathrm{N}}_{1} & 0 \\
f \overline{\mathrm{N}}_{2} & -e \overline{\mathrm{N}}_{2} & -g \overline{\mathrm{N}}_{2} \\
0 & -m \overline{\mathrm{N}}_{3} & -k \overline{\mathrm{N}}_{3}
\end{array}\right] \\
\text { In this case the characteristic equation is given by: } \\
\lambda^{3}+a_{1} \lambda^{2}+a_{2} \lambda+a_{3}=0
\end{gathered}
$$

where

$$
a_{1}=b \bar{N}_{1}+e \bar{N}_{2}+k \bar{N}_{3}, a_{2}=b k \bar{N}_{1} \bar{N}_{3}+(e k-g m) \bar{N}_{2} \bar{N}_{3}+(b e+c f) \bar{N}_{1} \bar{N}_{2} \text { and }
$$$$
a_{3}=(b e k+c f k-b g m) \bar{N}_{1} \bar{N}_{2} \bar{N}_{3}
$$

By Routh-Hurwitz criteria, all eigen values have negative real parts if and only if $D_{1}=a_{1}>0, D_{2}=a_{1} a_{2}-a_{3}>0$ and $D_{3}=a_{3}\left(a_{1} a_{2}-a_{3}\right)>0$

But $D_{1}=a_{1}>0, D_{2}=a_{1} a_{2}-a_{3}>0$ and $D_{3}=a_{3}\left(a_{1} a_{2}-a_{3}\right)>0$ if ek $>g m$

The positive interior equilibrium point $\left(\overline{\mathrm{N}}_{1}, \overline{\mathrm{N}}_{2}, \overline{\mathrm{N}}_{3}\right)$ is locally stable if $e k>g m$.

\subsubsection{Global Stability}

Theorem 2: The equilibrium point $\left(\overline{\mathrm{N}}_{1}, \overline{\mathrm{N}}_{2}, \overline{\mathrm{N}}_{3}\right)$ is globally asymptotically stable.

Proof:

Let consider the function which defined as:

$$
V\left(\overline{\mathrm{N}}_{1}, \overline{\mathrm{N}}_{2}, \overline{\mathrm{N}}_{3}\right)=\left\{\mathrm{N}_{1}-\overline{\mathrm{N}}_{1}-\overline{\mathrm{N}}_{1} \ln \left[\frac{\mathrm{N}_{1}}{\overline{\mathrm{N}}_{1}}\right]\right\}+\left\{\mathrm{N}_{2}-\overline{\mathrm{N}}_{2}-\overline{\mathrm{N}}_{2} \ln \left[\frac{\mathrm{N}_{2}}{\overline{\mathrm{N}}_{2}}\right]\right\}+\left\{\mathrm{N}_{3}-\overline{\mathrm{N}}_{3}-\overline{\mathrm{N}}_{3} \ln \left[\frac{\mathrm{N}_{3}}{\overline{\mathrm{N}}_{3}}\right]\right\}
$$

for $\mathrm{N}_{1}>\overline{\mathrm{N}}_{1}, \mathrm{~N}_{2}>\overline{\mathrm{N}}_{2}$ and $\mathrm{N}_{3}>\overline{\mathrm{N}}_{3}$.

Now we prove that the function $V$ is a Liapunov function. For this we need to show that:

Now

i. $V$ is continues and positive definite function

ii. $\frac{d V}{d t}$ is negative semi definite

i. The function $V$ is positive definite, since $N_{1}>\overline{\mathrm{N}}_{1}, N_{2}>\overline{\mathrm{N}}_{2}$ and $N_{3}>\overline{\mathrm{N}}_{3}$.

ii. Now, differentiating $V$ with respect to ' $t$ ' we obtain:

$$
\begin{aligned}
\frac{d V}{d t} & =\left(1-\frac{\overline{\mathrm{N}}_{1}}{\mathrm{~N}_{1}}\right) \frac{d \mathrm{~N}_{1}}{d t}+\left(1-\frac{\overline{\mathrm{N}}_{2}}{\mathrm{~N}_{2}}\right) \frac{d \mathrm{~N}_{2}}{d t}+\left(1-\frac{\overline{\mathrm{N}}_{3}}{\mathrm{~N}_{3}}\right) \frac{d \mathrm{~N}_{3}}{d t} \\
& =\left(\frac{\mathrm{N}_{1}-\overline{\mathrm{N}}_{1}}{\mathrm{~N}_{1}}\right) \frac{d \mathrm{~N}_{1}}{d t}+\left(\frac{\mathrm{N}_{2}-\overline{\mathrm{N}}_{2}}{\mathrm{~N}_{2}}\right) \frac{d \mathrm{~N}_{2}}{d t}+\left(\frac{\mathrm{N}_{3}-\mathrm{N}_{3}}{\mathrm{~N}_{3}}\right) \frac{d \mathrm{~N}_{3}}{d t}
\end{aligned}
$$

Substituting (3.1), (3.2) and (3.3) in to (3.43) we obtain:

$$
\begin{gathered}
\frac{d V}{d t}=\left(N_{1}-\bar{N}_{1}\right)\left[a-b N_{1}-c N_{1}-q_{1} N_{1}\right]+\left(N_{2}-\bar{N}_{2}\right)\left[d-e N_{2}+f N_{1}-g N_{3}-q_{2} N_{2}\right]+ \\
\left(N_{3}-\bar{N}_{3}\right)\left[h-k N_{3}-m N_{2}-q_{3} N_{3}\right] \\
=-b\left(N_{1}-\bar{N}_{1}\right)^{2}-\left\{e+\frac{1}{2}[c-f+g+m]\right\}\left(N_{2}-\bar{N}_{2}\right)^{2}-\left\{k+\frac{1}{2}[m+g]\right\}\left(N_{3}-\bar{N}_{3}\right)^{2}<0
\end{gathered}
$$

This implies that $\frac{d V}{d t}$ negative semi definite. Therefore, $\left(\bar{N}_{1}, \bar{N}_{2}, \bar{N}_{3}\right)$ is globally asymptotically stable.

Theorem 3: The systems (3.1) - (3.3) cannot have any limit cycle in the interior of the positive quadrant.

Proof: Let $\mathrm{H}\left(\mathrm{N}_{1}, \mathrm{~N}_{2}, \mathrm{~N}_{3}\right)=\frac{1}{\mathrm{~N}_{1} \mathrm{~N}_{2} \mathrm{~N}_{3}}$

$$
\begin{aligned}
& h_{1}\left(\mathrm{~N}_{1}, \mathrm{~N}_{2}, \mathrm{~N}_{3}\right)=a \mathrm{~N}_{1}-b\left(\mathrm{~N}_{1}\right)^{2}-c \mathrm{~N}_{1} \mathrm{~N}_{2}-\mathrm{q}_{1} \mathrm{E}_{1} \mathrm{~N}_{1} \\
& h_{2}\left(\mathrm{~N}_{1}, \mathrm{~N}_{2}, \mathrm{~N}_{3}\right)=d \mathrm{~N}_{2}-e\left(\mathrm{~N}_{2}\right)^{2}+f \mathrm{~N}_{1} \mathrm{~N}_{2}-g \mathrm{~N}_{2} \mathrm{~N}_{3}-\mathrm{q}_{2} \mathrm{E}_{2} \mathrm{~N}_{2} \text { and } \\
& h_{3}\left(\mathrm{~N}_{1}, \mathrm{~N}_{2}, \mathrm{~N}_{3}\right)=h \mathrm{~N}_{3}-k\left(\mathrm{~N}_{3}\right)^{2}-m \mathrm{~N}_{2} \mathrm{~N}_{3}-\mathrm{q}_{3} \mathrm{E}_{3} \mathrm{~N}_{3} . \text { Then }
\end{aligned}
$$

$\mathrm{H}\left(\mathrm{N}_{1}, \mathrm{~N}_{2}, \mathrm{~N}_{3}\right)>0$ in the interior of positive octant of $x y z$-space. Because $\mathrm{N}_{1}, \mathrm{~N}_{2}$ and $\mathrm{N}_{3}$ are all greater than zero.

$$
\text { Now } \begin{aligned}
\Delta\left(\mathrm{N}_{1}, \mathrm{~N}_{2}, \mathrm{~N}_{3}\right) & =\frac{\partial}{\partial \mathrm{N}_{1}}\left(\mathrm{H} h_{1}\right)+\frac{\partial}{\partial \mathrm{N}_{2}}\left(\mathrm{H} h_{2}\right)+\frac{\partial}{\partial \mathrm{N}_{3}}\left(\mathrm{H} h_{3}\right) \\
& =\frac{-b}{\mathrm{~N}_{2} \mathrm{~N}_{3}}-\frac{e}{\mathrm{~N}_{1} \mathrm{~N}_{3}}-\frac{k}{\mathrm{~N}_{1} \mathrm{~N}_{2}} \\
& =-\left[\frac{b}{\mathrm{~N}_{2} \mathrm{~N}_{3}}+\frac{e}{\mathrm{~N}_{1} \mathrm{~N}_{3}}+\frac{k}{\mathrm{~N}_{1} \mathrm{~N}_{2}}\right]<0
\end{aligned}
$$

This shows that $\Delta\left(\mathrm{N}_{1}, \mathrm{~N}_{2}, \mathrm{~N}_{3}\right)$ does not change sign and identically zero in the positive octant of ${ }^{x y z}$ space. By Bendixson - Dulac criteria, it follows that the system (3.1) - (3.3) has no closed trajectories and hence no periodic solutions in the positive octant of $x y z$ space. Thus the system (3.1) - (3.3) cannot have any limit cycles in the interior of the positive octant. 


\subsection{Bionomic equilibrium of the imprecise prey-predator model}

The bionomic equilibrium is nothing but the combination of the concepts of biological equilibrium as well as economic equilibrium. The biological equilibrium is given by equation (3.25). It is the study of the dynamics of living resources using economic models. Economic equilibrium is said to be achieved when the total revenue obtained by selling the harvested biomass (TR) equals to the total cost for the effort devoted to the harvesting (TC).

To discuss the bionomic equilibrium of the imprecise prey, predator and competitor to the predator model, we consider the following parameters.

Let $c_{1}$ be the harvesting cost per unit effort for prey species, $p_{1}$ be the price per unit biomass of the prey, $c_{2}$ be the harvesting cost per unit effort for predator species, $p_{2}$ be the price per unit biomass of the predator, $c_{3}$ be the harvesting cost per unit effort for competitor to the predator species and $p_{3}$ be the price per unit biomass of the competitor to the predator species, Then the net economic rent (net revenue) for the prey, predator and competitor to the predator at any time is given by:

$$
R=\left(p_{1} q_{1} \mathrm{~N}_{1}-c_{1}\right) \mathrm{E}_{1}+\left(p_{2} q_{2} \mathrm{~N}_{2}-c_{2}\right) \mathrm{E}_{2}+\left(p_{3} q_{3} \mathrm{~N}_{3}-c_{3}\right) \mathrm{E}_{3}=R_{1}+R_{2}+R_{3}
$$

Where $R_{1}=\left(p_{1} q_{1} \mathrm{~N}_{1}-c_{1}\right) \mathrm{E}_{1}, R_{2}=\left(p_{2} q_{2} \mathrm{~N}_{2}-c_{2}\right) \mathrm{E}_{2}$ and $R_{3}=\left(p_{3} q_{3} \mathrm{~N}_{3}-c_{3}\right) \mathrm{E}_{3}$.

$R_{1}, R_{2}$ and $R_{3}$ represent the net revenues for the prey, predator and competitor to the predator species respectively.

The bionomic equilibrium $\left\{\left(\mathrm{N}_{1}\right)_{\infty},\left(\mathrm{N}_{2}\right)_{\infty},\left(\mathrm{N}_{3}\right)_{\infty},\left(\mathrm{E}_{1}\right)_{\infty},\left(\mathrm{E}_{2}\right)_{\infty},\left(\mathrm{E}_{3}\right)_{\infty}\right\}$ is given by the following simultaneous equations.

$$
\left\{\begin{array}{l}
a \mathrm{~N}_{1}-b\left(\mathrm{~N}_{1}\right)^{2}-c \mathrm{~N}_{1} \mathrm{~N}_{2}-q_{1} \mathrm{E}_{1} \mathrm{~N}_{1}=0 \\
d \mathrm{~N}_{2}-e\left(\mathrm{~N}_{2}\right)^{2}+f \mathrm{~N}_{1} \mathrm{~N}_{2}-g \mathrm{~N}_{2} \mathrm{~N}_{3}-q_{2} \mathrm{E}_{2} \mathrm{~N}_{2}=0 \\
h \mathrm{~N}_{3}-k\left(\mathrm{~N}_{3}\right)^{2}-m \mathrm{~N}_{2} \mathrm{~N}_{3}-q_{3} \mathrm{E}_{3} \mathrm{~N}_{3}=0 \\
\left(p_{1} q_{1} \mathrm{~N}_{1}-c_{1}\right) \mathrm{E}_{1}+\left(p_{2} q_{2} \mathrm{~N}_{2}-c_{2}\right) \mathrm{E}_{2}+\left(p_{3} q_{3} \mathrm{~N}_{3}-c_{3}\right) \mathrm{E}_{3}=0
\end{array}\right.
$$

In order to determine the bionomic equilibrium we come across the following cases.

Case (1): When $c_{2}>p_{2} q_{2} \mathrm{~N}_{2}$ and $c_{3}>p_{3} q_{3} \mathrm{~N}_{3}$, the cost is greater than revenue for the predator and competitor to the predator species, then the predator and competitor to predator species are not harvested. The predator and competitor to the predator harvesting is stopped $\left(E_{2}=0, E_{3}=0\right)$. Then only prey harvesting remains operational $\left(c_{1}<p_{1} q_{1} \mathrm{~N}_{1}\right)$. Therefore $\mathrm{E}_{2}=\mathrm{E}_{3}=0$ and

$c_{1}<p_{1} q_{1} \mathrm{~N}_{1}$, we have $\left(N_{1}\right)_{\infty}=\frac{c_{1}}{p_{1} q_{1}}$.

Case (2): When $c_{1}>p_{1} q_{1} \mathrm{~N}_{1}$ and $c_{3}>p_{3} q_{3} \mathrm{~N}_{3}$ the cost is greater than revenue for the prey and competitor to the predator species, then the prey and competitor predator species are not harvested. The prey and competitor to the predator harvesting is $\operatorname{stopped}\left(\mathrm{E}_{1}=0, \mathrm{E}_{3}=0\right)$. Then only predator harvesting remains operational $c_{2}<p_{2} q_{2} \mathrm{~N}_{2}$. Therefore $\mathrm{E}_{1}=\mathrm{E}_{3}=0$ and $c_{2}<p_{2} q_{2} \mathrm{~N}_{2}$, we have $\left(\mathrm{N}_{2}\right)_{\infty}=\frac{c_{2}}{p_{2} q_{2}}$.

Case (3): When $c_{1}>p_{1} q_{1} \mathrm{~N}_{1}$ and $c_{2}>p_{2} q_{2} \mathrm{~N}_{2}$, the cost is greater than revenue for the prey and predator species, then the prey and predator species are not harvested. The prey and predator harvesting is stopped $\left(\mathrm{E}_{1}=\mathrm{E}_{2}=0\right)$. Then only predator harvesting remains operational

$\left(c_{3}<p_{3} q_{3} \mathrm{~N}_{3}\right)$. Therefore $\mathrm{E}_{1}=\mathrm{E}_{2}=0$ and $c_{3}<p_{3} q_{3} \mathrm{~N}_{3}$, we have $\left(\mathrm{N}_{3}\right)_{\infty}=\frac{c_{3}}{p_{3} q_{3}}$.

Case (4): When $c_{1}>p_{1} q_{1} \mathrm{~N}_{1}, c_{2}>p_{2} q_{2} \mathrm{~N}_{2}$ and $c_{3}>p_{3} q_{3} \mathrm{~N}_{3}$ then the cost is greater than revenues for both species and the whole harvesting will be closed.

Case (5): When $c_{1}<p_{1} q_{1} \mathrm{~N}_{1}, c_{2}<p_{2} q_{2} \mathrm{~N}_{2}$ and $c_{3}<p_{3} q_{3} \mathrm{~N}_{3}$ the cost is less than the revenue for both species, then both species is harvested. This implies that the revenues for both species being positive; so the whole harvesting will be in operation (the system becomes operational). In this case $\left(\mathrm{N}_{1}\right)_{\infty}=\frac{c_{1}}{p_{1} q_{1}},\left(\mathrm{~N}_{2}\right)_{\infty}=\frac{c_{2}}{p_{2} q_{2}}$ and $\left(\mathrm{N}_{3}\right)_{\infty}=\frac{c_{3}}{p_{3} q_{3}}$. By substituting the values of $\left(\mathrm{N}_{1}\right)_{\infty},\left(\mathrm{N}_{2}\right)_{\infty}$ and $\left(\mathrm{N}_{3}\right)_{\infty}$ in to the $1^{\text {st }}, 2^{\text {nd }}$, and $3^{\text {rd }}$ equation of (3.44) we obtain:

$$
\begin{gathered}
\left(\mathrm{E}_{1}\right)_{\infty}=\frac{1}{q_{1}}\left[\frac{a p_{1} p_{2} q_{1} q_{2}-b p_{2} q_{2} c_{1}-c p_{1} q_{1} c_{2}}{p_{1} p_{2} q_{1} q_{2}}\right] \\
\left(\mathrm{E}_{2}\right)_{\infty}=\frac{1}{q_{2}}\left[\frac{d p_{1} p_{2} p_{3} q_{1} q_{2} q_{3}-e p_{1} p_{3} q_{1} q_{3} c_{2}+f p_{2} p_{3} q_{2} q_{3} c_{1}-g p_{1} p_{2} q_{1} q_{2} c_{3}}{p_{1} p_{2} p_{3} q_{1} q_{2} q_{3}}\right] \\
\left(\mathrm{E}_{3}\right)_{\infty}=\frac{1}{q_{3}}\left[\frac{h p_{2} p_{3} q_{2} q_{3}-k p_{2} q_{2} c_{3}-m p_{3} q_{3} c_{2}}{p_{2} p_{3} q_{2} q_{3}}\right]
\end{gathered}
$$

But

$$
\begin{gathered}
\left(\mathrm{E}_{1}\right)_{\infty}>0 \text { if } a p_{1} p_{2} q_{1} q_{2}>b p_{2} q_{2} c_{1}+c p_{1} q_{1} c_{2} \\
\left(\mathrm{E}_{2}\right)_{\infty}>0 \text { if } d p_{1} p_{2} p_{3} q_{1} q_{2} q_{3}+f p_{2} p_{3} q_{2} q_{3} c_{1}>e p_{1} p_{3} q_{1} q_{3} c_{2}+g p_{1} p_{2} q_{1} q_{2} c_{3} \\
\left(\mathrm{E}_{3}\right)_{\infty}>0 \text { if } h p_{2} p_{3} q_{2} q_{3}>k p_{2} q_{2} c_{3}+m p_{3} q_{3} c_{2}
\end{gathered}
$$

Thus the nontrivial bionomic equilibrium point $\left[\left(\mathrm{N}_{1}\right)_{\infty},\left(\mathrm{N}_{2}\right)_{\infty},\left(\mathrm{N}_{3}\right)_{\infty},\left(\mathrm{E}_{1}\right)_{\infty},\left(\mathrm{E}_{2}\right)_{\infty},\left(\mathrm{E}_{3}\right)_{\infty}\right]$ exist if conditions (3.48) - (3.50) hold. 


\subsection{Qualitative Analysis Of Optimal Harvesting Policy}

In commercial exploitation of renewable resources the fundamental problem from the economic point of view, is to determine the optimal trade-off between present and future harvests. If we look at the problem it is observed that the marine fishery sectors become more important not only for domestic demand but also from the imperatives of exports.

In this section we study optimal harvesting policy of the system of equation (3.1) - (3.3); and also our objective is to maximize, the objective functional form of the harvesting model, with the instantaneous annual rate of discount $\delta$ is as follows:

$$
\mathcal{J}\left(\mathrm{E}_{1}, \mathrm{E}_{2}, \mathrm{E}_{3}\right)=\int_{0}^{\infty} e^{-\delta t}\left[\left(p_{1} q_{1} \mathrm{~N}_{1}-c_{1}\right) \mathrm{E}_{1}(t)+\left(p_{2} q_{2} \mathrm{~N}_{2}-c_{2}\right) \mathrm{E}_{2}(t)+\left(p_{3} q_{3} \mathrm{~N}_{3}-c_{3}\right) \mathrm{E}_{3}(t)\right] d t(3.51)
$$

Subject to the state constraints (3.1) - (3.3) with control constraints (variables):

$$
0 \leq \mathrm{E}_{i}(t) \leq \mathrm{E}_{i}^{\max }, i=1,2,3
$$

Firs we construct the following Hamiltonian function for the problem by:

$$
\begin{aligned}
\mathrm{H}=e^{-\delta t}\left[\left(p_{1}\right.\right. & \left.\left.q_{1} \mathrm{~N}_{1}-c_{1}\right) \mathrm{E}_{1}(t)+\left(p_{2} q_{2} \mathrm{~N}_{2}-c_{2}\right) \mathrm{E}_{2}(t)+\left(p_{3} q_{3} \mathrm{~N}_{3}-c_{3}\right) \mathrm{E}_{3}(t)\right] \\
& +\lambda_{1}\left[a \mathrm{~N}_{1}-b\left(\mathrm{~N}_{1}\right)^{2}-c \mathrm{~N}_{1} \mathrm{~N}_{2}-q_{1} \mathrm{E}_{1} \mathrm{~N}_{1}\right] \\
& +\lambda_{2}\left[d \mathrm{~N}_{2}-e\left(\mathrm{~N}_{2}\right)^{2}+f \mathrm{~N}_{1} \mathrm{~N}_{2}-g \mathrm{~N}_{2} \mathrm{~N}_{3}-q_{2} \mathrm{E}_{2} \mathrm{~N}_{2}\right] \\
& +\lambda_{3}\left[h \mathrm{~N}_{3}-k\left(\mathrm{~N}_{3}\right)^{2}-m \mathrm{~N}_{2} \mathrm{~N}_{3}-q_{3} \mathrm{E}_{3} \mathrm{~N}_{3}\right]
\end{aligned}
$$

where $\lambda_{1}, \lambda_{2}$ and $\lambda_{3}$ are additional unknown functions called the adjoint variables.

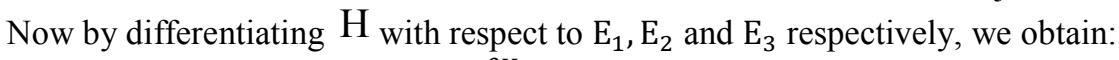

$$
\begin{aligned}
& \frac{\partial \mathrm{H}}{\partial \mathrm{E}_{1}}=e^{-\delta t}\left(p_{1} q_{1} \mathrm{~N}_{1}-c_{1}\right)-\lambda_{1} q_{1} \mathrm{~N}_{1}=\varphi_{1}(t) \\
& \frac{\partial \mathrm{H}}{\partial \mathrm{E}_{2}}=e^{-\delta t}\left(p_{2} q_{2} \mathrm{~N}_{2}-c_{2}\right)-\lambda_{2} q_{2} \mathrm{~N}_{2}=\varphi_{2}(t) \\
& \frac{\partial \mathrm{H}}{\partial \mathrm{E}_{3}}=e^{-\delta t}\left(p_{3} q_{3} \mathrm{~N}_{3}-c_{3}\right)-\lambda_{3} q_{3} \mathrm{~N}_{3}=\varphi_{3}(t)
\end{aligned}
$$

The optimal control $\mathrm{E}_{i}(t)$ must satisfy the condition:

$$
E_{i}(t)=\left\{\begin{array}{l}
E_{i}^{\max } \text { if } \varphi_{i}(t)>0 \\
0 \quad \text { if } \varphi_{i}(t)>0
\end{array}\right.
$$

Since $\varphi_{i}(t)$ causes $\mathrm{E}_{i}(t),(i=1,2,3)$ to switch between 0 and $E_{i}^{\max }$ so $\varphi_{i}(t)(i=1,2,3)$ are called switching function. Depending on the sign of the switching function $\varphi_{i}(t)$, the optimal control $\mathrm{E}_{i}(t)$ is a bang- bang switching from one extreme point to other one. When $\varphi_{i}(t)=0(i=1,2,3)$, the Hamiltonian function $\mathrm{H}$ becomes independent of the control variable $\mathrm{E}_{i}(t),(i=1,2,3)$ and the optimal control cannot be determined by the above procedure. It is then called a singular control

$\mathrm{E}_{i}^{*}(t), 0<\mathrm{E}_{i}^{*}(t)<\mathrm{E}_{i}^{\max }(t)$. Hence the optimal harvesting policy is

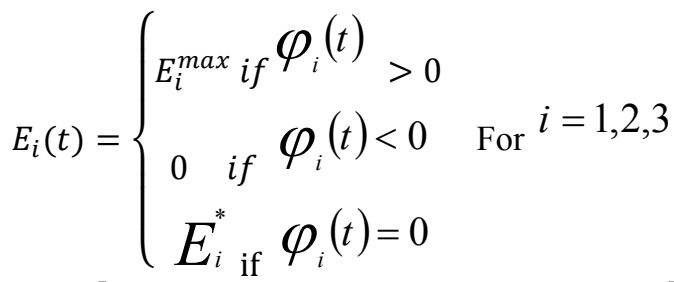

The aim is to find an optimal equilibrium $\left[\left(\mathrm{N}_{1}\right)_{\delta},\left(\mathrm{N}_{2}\right)_{\delta},\left(\mathrm{N}_{3}\right)_{\delta},\left(\mathrm{E}_{1}\right)_{\delta},\left(\mathrm{E}_{2}\right)_{\delta},\left(\mathrm{E}_{3}\right)_{\delta}\right]$ to maximize Hamiltonian

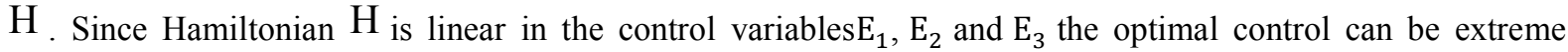
controls or the singular controls.

Thus for singular control $\varphi_{i}(t)=0(i=1,2,3)$, from equations (3.53) - (3.55) solving for $\lambda_{i},(i=1,2,3)$ we obtain:

$$
\begin{aligned}
& \lambda_{1}=e^{-\delta t}\left(p_{1}-\frac{c_{1}}{q_{1} \mathrm{~N}_{1}}\right) \\
& \lambda_{2}=e^{-\delta t}\left(p_{2}-\frac{c_{2}}{q_{2} \mathrm{~N}_{2}}\right) \\
& \lambda_{3}=e^{-\delta t}\left(p_{3}-\frac{c_{3}}{q_{3} \mathrm{~N}_{3}}\right)
\end{aligned}
$$

In this case, the optimal control is called the singular control and equations (3.58) - (3.60) are the necessary conditions for the maximization of Hamiltonian $\mathrm{H}$.

By Pontryagin's Maximum Principle, the adjoint equations are: 
Now, by using equation (3.61) we obtain:

$$
\frac{\mathrm{d} \lambda_{1}}{\mathrm{dt}}=-\frac{\partial \mathrm{H}}{\partial \mathrm{N}_{1}}, \frac{\mathrm{d} \lambda_{2}}{\mathrm{dt}}=-\frac{\partial \mathrm{H}}{\partial \mathrm{N}_{2}}, \frac{\mathrm{d} \lambda_{3}}{\mathrm{dt}}=-\frac{\partial \mathrm{H}}{\partial \mathrm{N}_{3}}
$$

$$
\frac{d \lambda_{1}}{d t}=-e^{-\delta t} p_{1} q_{1} \mathrm{E}_{1}-\lambda_{1}\left[a-2 b \mathrm{~N}_{1}-c \mathrm{~N}_{2}-q_{1} \mathrm{E}_{1}\right]-\lambda_{2} f \mathrm{~N}_{2}
$$

Substituting $a=b \mathrm{~N}_{1}+c \mathrm{~N}_{2}+q_{1} \mathrm{E}_{1}$ and (3.59) in to the equation (3.62) we obtain:

This is of the form: $\frac{d \lambda_{1}}{d t}+\mathrm{A}_{1} \lambda_{1}=-A_{2} e^{-\delta t}$

$$
\begin{aligned}
& \frac{d \lambda_{1}}{d t}=-e^{-\delta t} p_{1} q_{1} \mathrm{E}_{1}+b \mathrm{~N}_{1} \lambda_{1}-e^{-\delta t}\left(p_{2}-\frac{c_{2}}{q_{2} \mathrm{~N}_{2}}\right) \text { or } \\
& \frac{d \lambda_{1}}{d t}-b \mathrm{~N}_{1} \lambda_{1}=-e^{-\delta t} p_{1} q_{1} \mathrm{E}_{1}-e^{-\delta t}\left(p_{2}-\frac{c_{2}}{q_{2} \mathrm{~N}_{2}}\right)
\end{aligned}
$$

where $\mathrm{A}_{1}=-b \mathrm{~N}_{1}$ and $\mathrm{A}_{2}=p_{1} q_{1} \mathrm{E}_{1}+\left(p_{2}-\frac{c_{2}}{q_{2} \mathrm{~N}_{2}}\right)$

The above equation is linear in $\lambda_{1}$ and its solution is given by:

and also

$$
\lambda_{1}=-\frac{\mathrm{A}_{2}}{\mathrm{~A}_{1}-\delta} e^{-\delta t}
$$

$$
\frac{d \lambda_{2}}{d t}=-e^{-\delta t} p_{2} q_{2} \mathrm{E}_{2}+c \mathrm{~N}_{1} \lambda_{1}-\lambda_{2}\left(d-2 e \mathrm{~N}_{2}+f \mathrm{~N}_{1}-g \mathrm{~N}_{3}-q_{2} \mathrm{E}_{2}\right)+m \mathrm{~N}_{3} \lambda_{3}
$$

Substituting $d=e \mathrm{~N}_{2}-f \mathrm{~N}_{1}+g \mathrm{~N}_{3}+q_{2} \mathrm{E}_{2}$ and equations (3.58) in to (3.65) we obtain:

$$
\frac{d \lambda_{2}}{d t}+\mathrm{B}_{1} \lambda_{2}=B_{2} e^{-\delta t}
$$

where $B_{1}=-e \mathrm{~N}_{2}$ and $B_{2}=\left(p_{1}-\frac{c_{1}}{q_{1} \mathrm{~N}_{1}}\right) c \mathrm{~N}_{1}+\left(p_{3}-\frac{c_{3}}{q_{3} \mathrm{~N}_{3}}\right) m \mathrm{~N}_{3}-p_{2} q_{2} \mathrm{E}_{2}$

The above equation is linear in $\lambda_{2}$ and its solution is given by:

Similarly,

$$
\lambda_{2}=\frac{B_{2}}{B_{1}-\delta} e^{-\delta t}
$$

Now by substituting $h=k \mathrm{~N}_{3}+m \mathrm{~N}_{2}+q_{3} \mathrm{E}_{3}$, equation (3.58) and (3.59) in to (3.68) we obtain:

$\frac{d \lambda_{3}}{d t}+\mathrm{C}_{1} \lambda_{3}=C_{2} e^{-\delta t}$

Where $C_{1}=-k \mathrm{~N}_{3}$ and $C_{2}=\left(p_{2}-\frac{c_{2}}{q_{2} \mathrm{~N}_{2}}\right) g \mathrm{~N}_{2}-p_{3} q_{3} \mathrm{~N}_{3}$

The above equation is linear in $\lambda_{3}$ and its solution is given by:

$$
\lambda_{3}=\frac{C_{2}}{c_{1}-\delta} e^{-\delta t}
$$

It is obviously that $\lambda_{1}(t), \lambda_{2}(t)$ and $\lambda_{3}(t)$ are bounded as $t \rightarrow \infty$. From (3.58) and (3.64) we obtain a singular path:

$$
\mathrm{p}_{1}-\frac{\mathrm{c}_{1}}{\mathrm{q}_{1} \mathrm{~N}_{1}}=-\frac{\mathrm{A}_{2}}{\mathrm{~A}_{1}-\delta}
$$

And also from (3.59) and (3.67), we obtain a singular path:

$$
p_{2}-\frac{c_{2}}{q_{2} N_{2}}=\frac{B_{2}}{B_{1}-\delta}
$$

Similarly, from (3.60) and (3.70) we obtain a singular path:

$$
p_{3}-\frac{C_{3}}{q_{3} \mathrm{~N}_{3}}=\frac{\mathrm{C}_{2}}{\mathrm{C}_{1}-\delta}
$$

Let $\mathrm{F}\left(\overline{\mathrm{N}}_{1}\right)=\left(p_{1}-\frac{c_{1}}{q_{1} \mathrm{~N}_{1}}\right)+\frac{\mathrm{A}_{2}}{\mathrm{~A}_{1}-\delta}, G\left(\overline{\mathrm{N}}_{2}\right)=\left(p_{2}-\frac{c_{2}}{q_{2} \mathrm{~N}_{2}}\right)-\frac{\mathrm{B}_{2}}{\mathrm{~B}_{1}-\delta}$ and $\mathcal{M}\left(\overline{\mathrm{N}}_{3}\right)=\left(p_{3}-\frac{c_{3}}{q_{3} \mathrm{~N}_{3}}\right)-\frac{\mathrm{C}_{2}}{\mathrm{C}_{1}-\delta}$ then there exists a unique positive root $\overline{\mathrm{N}}_{1}=\left(\mathrm{N}_{1}\right)_{\delta}$ of $\mathrm{F}\left(\overline{\mathrm{N}}_{1}\right)=0$ in the interval $0<\overline{\mathrm{N}}_{1}<k_{1}$ if the following inequalities hold:

$$
\mathrm{F}(0)<0, \mathrm{~F}\left(\mathrm{k}_{1}\right)>0, \mathrm{~F}^{\prime}\left(\overline{\mathrm{N}}_{1}\right)>0 \text { for } \overline{\mathrm{N}}_{1}>0
$$

And also there exists a unique positive root $\overline{\mathrm{N}}_{2}=\left(\mathrm{N}_{2}\right)_{\delta}$ of $G\left(\overline{\mathrm{N}}_{2}\right)=0$ in the interval $0<\overline{\mathrm{N}}_{2}<k_{2}$ if the following inequalities hold:

$$
G(0)<0, G\left(\mathrm{k}_{2}\right)>0, G^{\prime}\left(\overline{\mathrm{N}}_{2}\right)>0 \text { for } \overline{\mathrm{N}}_{2}>0
$$

Similarly, there exists a unique positive root $\overline{\mathrm{N}}_{3}=\left(\mathrm{N}_{3}\right)_{\delta}$ of $\mathcal{M}\left(\overline{\mathrm{N}}_{3}\right)=0$ in the interval $0<\overline{\mathrm{N}}_{3}<k_{3}$ if the following inequalities hold:

$$
\mathcal{M}(0)<0, \mathcal{M}\left(\mathrm{k}_{3}\right)>0, \mathcal{M}^{\prime}\left(\overline{\mathrm{N}}_{3}\right)>0 \text { for } \overline{\mathrm{N}}_{3}>0
$$


Now, for $\overline{\mathrm{N}}_{1}=\left(\mathrm{N}_{1}\right)_{\delta}, \overline{\mathrm{N}}_{2}=\left(\mathrm{N}_{2}\right)_{\delta}$ and $\overline{\mathrm{N}}_{3}=\left(\mathrm{N}_{3}\right)_{\delta}$ we get:

$$
\begin{gathered}
\left(\mathrm{N}_{1}\right)_{\infty}=\frac{\mathrm{c}_{1}}{\mathrm{p}_{1} \mathrm{q}_{1}},\left(\mathrm{~N}_{2}\right)_{\infty}=\frac{\mathrm{c}_{2}}{\mathrm{p}_{2} \mathrm{q}_{2}},\left(\mathrm{~N}_{3}\right)_{\infty}=\frac{\mathrm{c}_{3}}{\mathrm{p}_{3} \mathrm{q}_{3}}, \\
\left(\mathrm{E}_{1}\right)_{\delta}=\frac{a p_{1} p_{2} q_{1} q_{2}-b p_{2} q_{2} c_{1}-c p_{1} q_{1} c_{2}}{p_{1} p_{2}\left(q_{1}\right)^{2} q_{2}} \\
\left(\mathrm{E}_{2}\right)_{\delta}=\frac{d p_{1} p_{2} p_{3} q_{1} q_{2} \mathrm{q}_{3}-e p_{1} p_{3} q_{1} q_{3} c_{2}+f p_{2} p_{3} p_{3} q_{2} q_{3} \mathrm{c}_{1}-g p_{1} p_{2} q_{1} q_{2} c_{3}}{p_{1} p_{2} p_{3} q_{1}\left(q_{2}\right)^{2} q_{3}} \\
\text { and } \quad \\
\left(\mathrm{E}_{3}\right)_{\delta}=\frac{\mathrm{h} p_{2} p_{3} q_{2} q_{3}-k p_{2} q_{2} c_{3}-m p_{3} q_{3} c_{2}}{p_{2} p_{3} q_{2}\left(q_{3}\right)^{2}}
\end{gathered}
$$

Hence once the optimal equilibrium $\left(\left(\mathrm{N}_{1}\right)_{\delta},\left(\mathrm{N}_{2}\right)_{\delta}\left(\mathrm{N}_{3}\right)_{\delta}\right)$ is determined, the optimal harvesting effort $\left(\left(\mathrm{E}_{1}\right)_{\delta}\right.$, $\left.\left(\mathrm{E}_{2}\right)_{\delta},\left(\mathrm{E}_{3}\right)_{\delta}\right)$ can be determined. From (3.64), (3.67) and (3.70) we found that $\lambda_{i}(t)$ where $i=1,2,3$ do not vary with time in optimal equilibrium. Hence they remains bounded as $t \rightarrow \infty$.

From (3.71), (3.72) and (3.73) we note that:

$$
\begin{aligned}
& \mathrm{p}_{1}-\frac{\mathrm{c}_{1}}{\mathrm{q}_{1} \mathrm{~N}_{1}}=-\frac{\mathrm{A}_{2}}{\mathrm{~A}_{1}-\delta} \rightarrow 0 \text { as } \delta \rightarrow 0 \\
& \text { and } \begin{aligned}
\mathrm{p}_{2}-\frac{\mathrm{C}_{2}}{\mathrm{q}_{2} \mathrm{~N}_{2}} & =\frac{\mathrm{B}_{2}}{\mathrm{~B}_{1}-\delta} \rightarrow 0 \text { as } \delta \rightarrow 0 \\
\mathrm{p}_{3}-\frac{\mathrm{C}_{3}}{\mathrm{q}_{3} \mathrm{~N}_{3}} & =\frac{\mathrm{C}_{2}}{\mathrm{C}_{1}-\delta} \rightarrow 0 \text { as } \delta \rightarrow 0
\end{aligned}
\end{aligned}
$$

Thus, the net economic revenue for the Prey population $R_{1}=0$, the net economic revenue for the predator population $R_{2}=0$ and the net economic revenue for the competitor to the Predator population $R_{3}=0$. From this we conclude that, if the discount rate increases, then the net economic revenue decrease and even may tend to zero if the discount rate tends to infinity. Hence finally we remarked that high interest rate will cause high inflation rate.

\section{Numerical simulation}

In this section, we substantiate as well as augment our analytical findings through numerical simulations considering the interval parameters. For this, numerical examples are obtained to illustrate the proposed methodology presented in this paper.

Example: Let us consider a set of artificial values of parameters as follows in appropriate units:

$$
\begin{aligned}
& r=[2.5,3], \alpha_{1}=[0.2,0.6], \alpha_{2}=[0.7,0.8], \alpha_{3}=[0.5,0.9], s=[4.5,5], \beta_{1}=[0.8,0.9], \\
& \beta_{2}=[0.2,0.4], \beta_{3}=[0.5,0.6], \ell=[5.5,6], \delta_{1}=[0.2,0.5], q_{1}=0.2, q_{2}=0.5, q_{3}=0.8, \mathrm{E}_{1}=10, \mathrm{E}_{2}=8,
\end{aligned}
$$$$
\mathrm{E}_{3}=6 \text { and } p \in[0,1] \text {. }
$$

The trivial equilibrium point $(0,0,0)$ always exists for all values of $p \in[0,1]$. The non trivial equilibrium points and the Eigen values of variational matrices at the corresponding points of co-existence equilibriums are given in table1below for different values of $p_{\text {in }}[0,1]$. 
Table 3.2 Equilibrium states, eigen values, nature of the equilibrium points.

\begin{tabular}{|c|c|c|c|}
\hline Values of $p$ & Equilibrium states & Eigen values & Nature of the equilibrium states \\
\hline 0 & $0.29,0.362,0.536$ & $\begin{array}{l}-0.636,-0.156-0.111 i \\
-0.156+0.111 i\end{array}$ & Stable \\
\hline 0.1 & $0.294,0.435,0.578$ & $\begin{array}{l}-0.674,-0.144-0.117 i \\
-0.144+0.117 i\end{array}$ & Stable \\
\hline 0.2 & $0.292,0.515,0.623$ & $\begin{array}{l}-0.665,-0.18-0.126 i \\
-0.18+0.126 i\end{array}$ & Stable \\
\hline 0.3 & $0.275,0.601,0.661$ & $\begin{array}{l}-0.793,-0.164-0.125 i \\
-0.164+0.125 i\end{array}$ & Stable \\
\hline 0.4 & $0.281,0.674,0.729$ & $\begin{array}{l}-0.783,-0.188-0.156 i \\
-0.188+0.156 i\end{array}$ & Stable \\
\hline 0.5 & $0.275,0.755,0.791$ & $\begin{array}{l}-0.812,-0.179-0.155 i \\
-0.179+0.155 i\end{array}$ & Stable \\
\hline 0.6 & $0.261,0.842,0.856$ & $\begin{array}{l}-0.846,-0.168-0.148 i \\
-0.168+0.148 i\end{array}$ & Stable \\
\hline 0.7 & $0.322,0.929,0.967$ & $\begin{array}{l}-0.943,-0.193-0.178 i \\
-0.193+0.178 i\end{array}$ & Stable \\
\hline 0.8 & $0.149,1.079,0.928$ & $-0.962,-0.254,-0.128$ & Stable \\
\hline 0.9 & $0.195,1.134,1.162$ & $\begin{array}{l}-1.017,-0.197-0.124 i \\
-0.197+0.124 i\end{array}$ & Stable \\
\hline 1 & $0.2,1.2,1.2$ & $\begin{array}{l}-1.072,-0.204-0.122 i \\
-0.204+0.122 i\end{array}$ & Stable \\
\hline
\end{tabular}

From the above table we observe that there are different equilibrium points for different values of $p$. We also see that the eigen values corresponding to different equilibrium points are complex conjugate with negative real part. Therefore the equilibrium points are stable.

The fluctuation of prey, predator and competitor to the predator population with respect to time beginning with $\mathrm{N}_{1}=1, \mathrm{~N}_{2}=1.09$ and $\mathrm{N}_{3}=1.1$ for $p=0.7, p=0.8, p=0.9$ and $p=1$ are depicted in following Figures respectively.

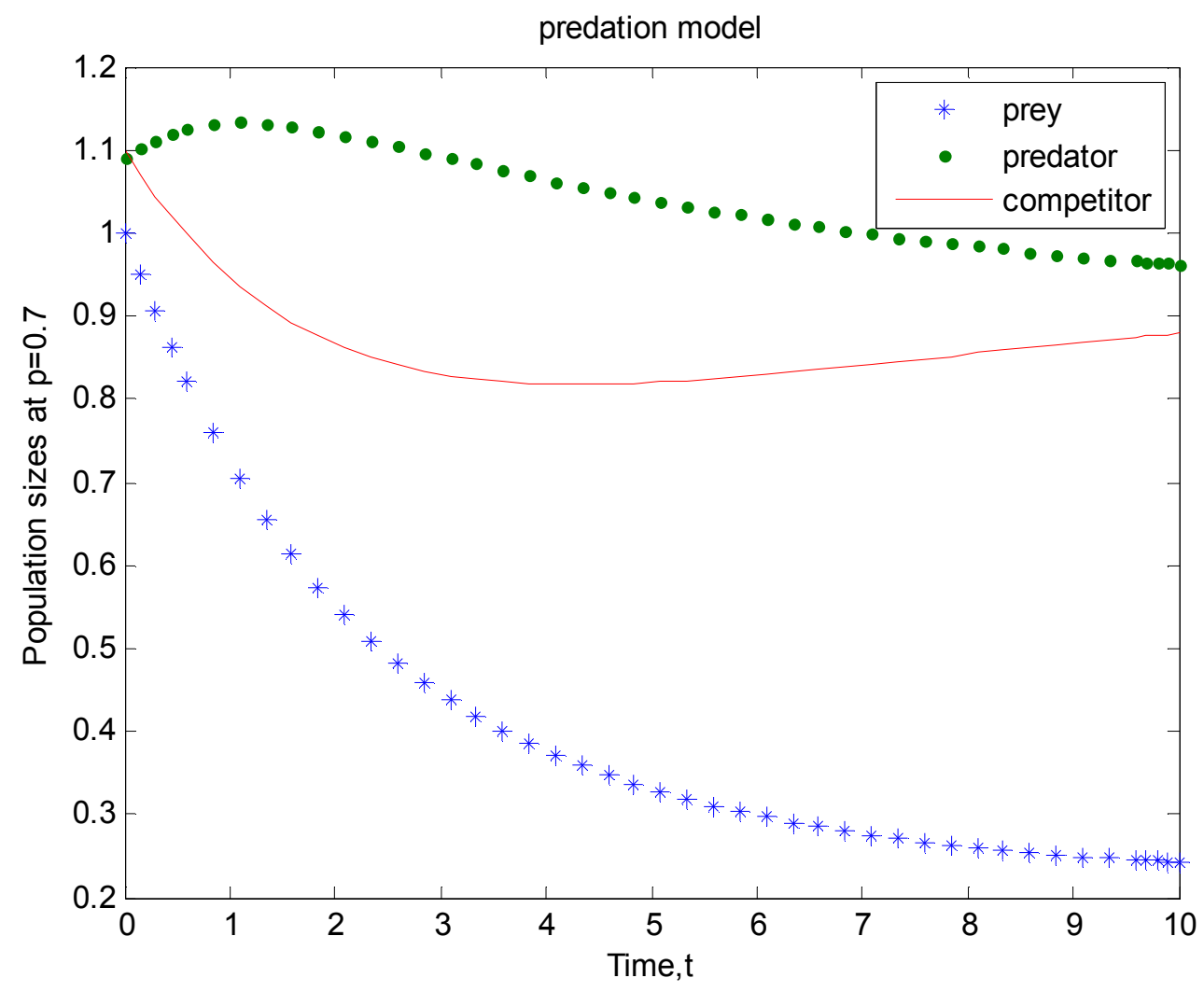



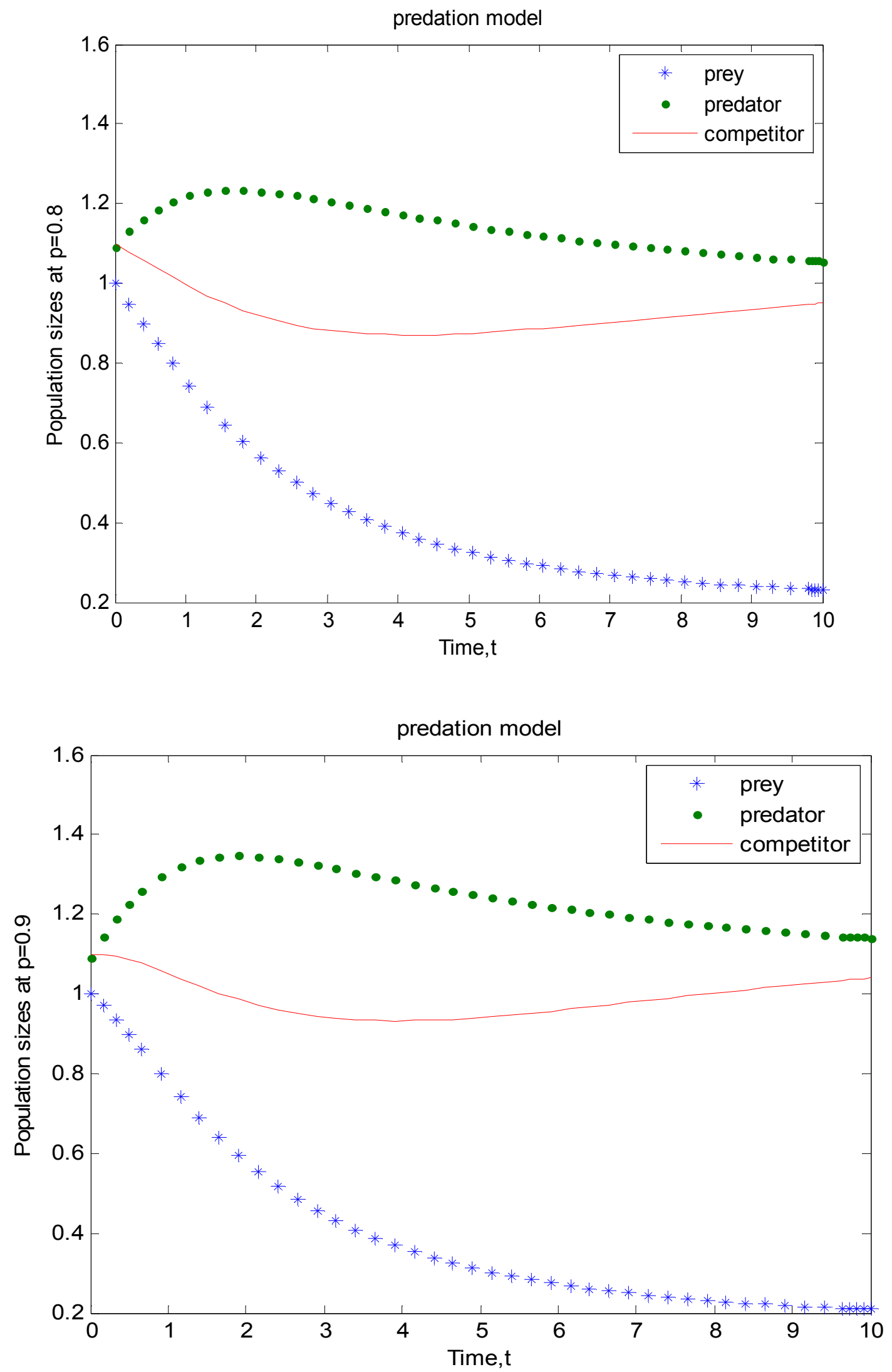


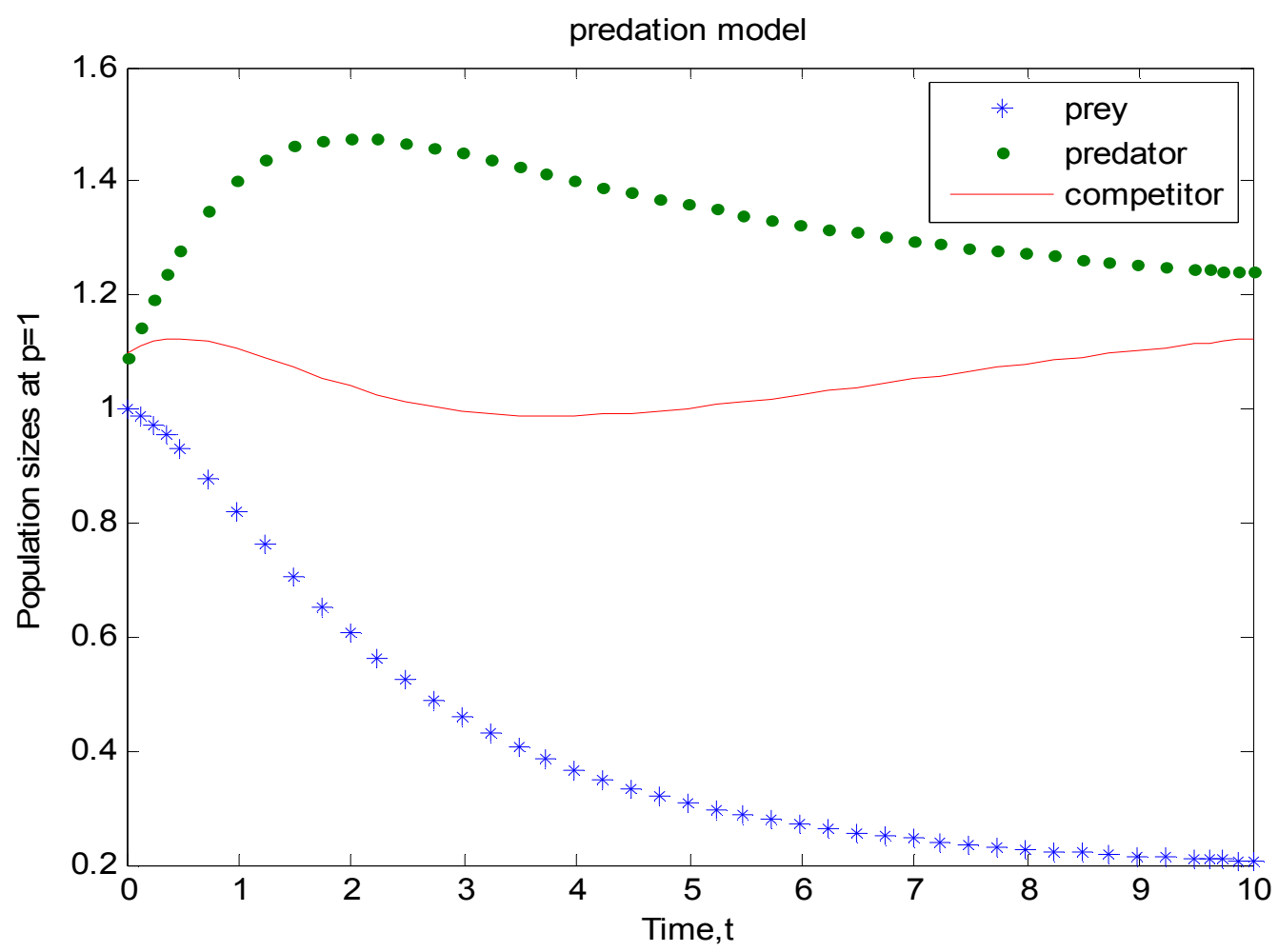

Fig 1: Variation of prey, predator and competitor to the predator population against the time for different values of $\mathrm{p}$

\section{CONCLUSIONS AND RECOMMENDATIONS \\ 4.1 Conclusions}

Prey-predator (competitor) harvesting model has undergone different development in theoretical and practical applications in the field of biomathematics. Most of the researchers have developed the prey, predator and competitor to the predator harvesting model based on the assumption that the biological parameters are precisely known but the scenario is different in real life situation. In this paper, we developed a method to find the biological equilibrium points, bio-economic equilibrium points and optimal harvesting policy when some biological parameters are imprecise in nature. Here we develop the concepts imprecise parameters to the prey, predator and competitor to the predator harvesting model by considering the prey population growth rate, predator population growth rate, competitor to the predator growth rate and predation coefficients are imprecise in nature for the lack of precise numerical information. The ability of calculating the biological equilibrium points, bio-economic equilibrium points and optimal harvesting policy developed in this paper might help to develop more realistic mathematical models in the area of mathematical biology. Before ending this article we would like to mention that one may consider Lotka-Volterra model with logistic growth under imprecise biological parameters. Impreciseness of the harvesting cost and price of the biomass of the species of the harvesting model are also important characteristic to be considered.

\subsection{Recommendation}

Basing on the results of qualitative analysis and numerical simulation of the model, we recommend that;

i. Prey-predator (competitor) should not be harvested at a rate higher than their growth rate. However optimal harvesting of the prey-predator (competitor) at a rate much lower than their growth rate is permissible, since this would not lead to collapse of the system in the long term.

ii. The population density of the predator can be increased drastically by increasing the growth rate of the prey species e.g. regular recruiting more prey into the area. Since regular recruiting of prey may not be realistic, the best alternative is to minimize or stop poaching of the preys so as to greatly increase the number of their population in that area, which will in turn result in an increase in the population of the predator. But the number of population of competitor to the predator does not dependent on the number of prey population; it depends on the number of predator population that competes' with them for common resource. This common resource may be additional resources for predator population.

iii. The population density of the predator depends mainly on the biomass of the prey than that of 
competitor; hence any attempt to control the population density of the predator should be based on controlling the population density of the prey.

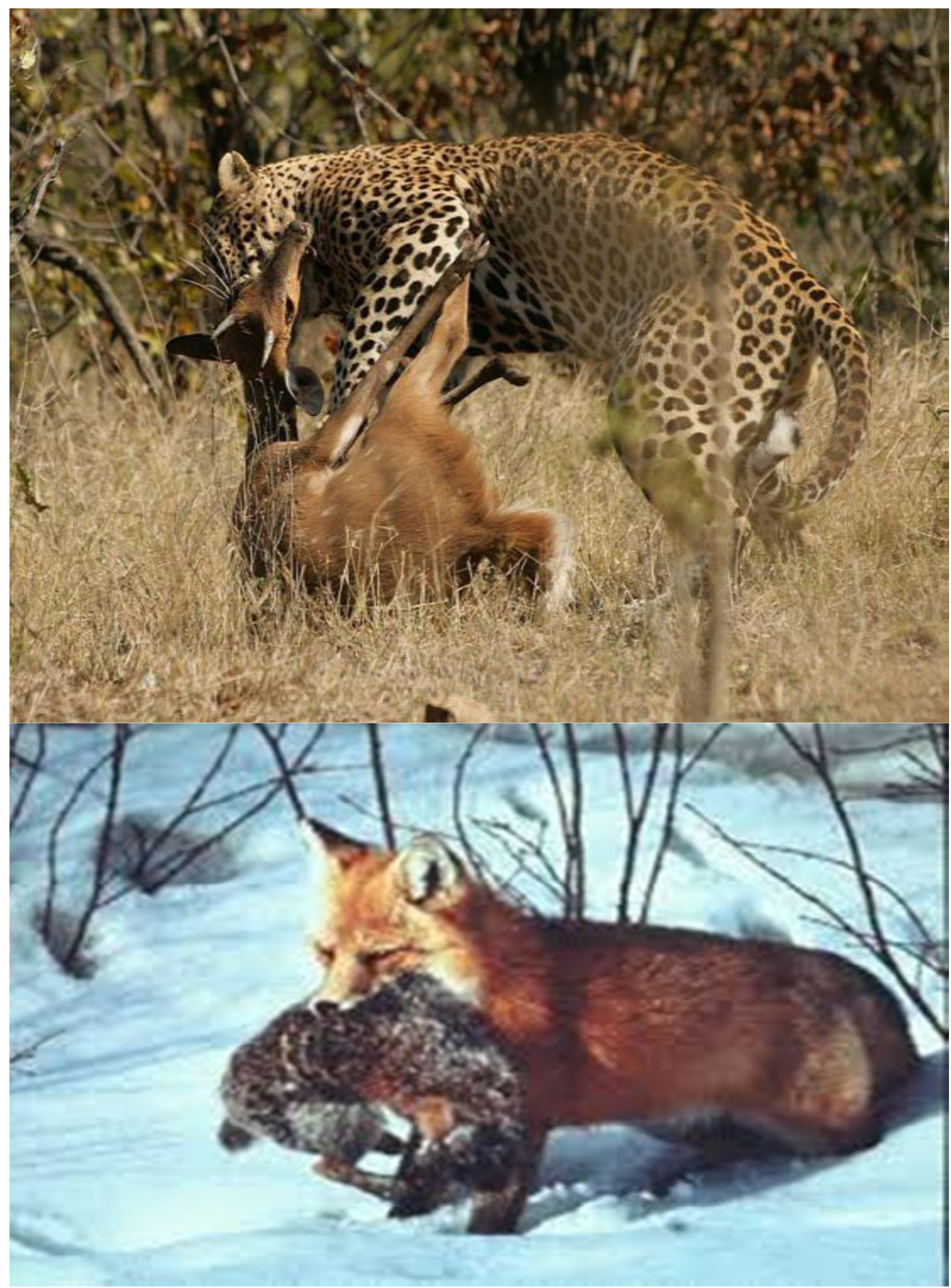

Fig.2 prey-predator examples

\section{References}

* A. J. Lotka, Elements of Physical Biology, Williams and Wilkins, Baltimore, New York, 1925.

* A.R. Palma, E.G. Olivares, Optimal harvesting in a predator-prey model with Allee effect and sigmoid functional response, Appl. Math. Model. 5 (2012)1864.

* B. Dubey, P. Chandra, P. Sinha, A model for fishery resource with reserve area, Nonlinear Anal. Real 
World Appl. 4 (2003) 625.

* C. Chen, C. Hsui, Fishery policy when considering the future opportunity of harvesting, Math. Biosci. 207 (2007) 138.

* C.W. Clark, Bioeconomic Modeling and Fisheries Management, Wiley, New York, 1985.

* D. Pal et al. / Mathematical Biosciences 241 (2013) 181-187

* D.L. Ragogin, G. Brown, Harvest policies and non-market valuation in a predator prey system, J. Environ. Econ. Manag. 12(1985)155.

* G.P. Samanta, D. Manna, A. Maiti, A bioeconomic modelling of a three species fishery with switching effect, J. Appl. Math. Comp. 12 (2003) 219.

* G.S. Mahapatra, B.S. Mahapatra, Reliability and cost analysis of series system models using fuzzy parametric geometric programming, Fuzzy Inf. Eng. 2(2010) 399.

* G.S. Mahapatra, T.K. Mandal, Posynomial parametric geometric programming with interval valued coefficient, J. Optim. Theory Appl.154 (2012) 120.

* J. Pastor, Mathematical Ecology of Populations and Ecosystems, Wiley-Blackwell, 2008.

* K. Lakshmi Narayan et al Adv. Appl. Sci. Res., 2011, 2 (4):451-459

* K.S. Chaudhuri, Dynamic optimization of combined harvesting of two species fishery, Ecol. Model. 41(1988)17.

* K.S. Chaudhuri, S. Saha Roy, On the combined harvesting of a prey-predator system, J. Biol. Syst. 4 (1996) 376.

* L. Yunfei, P. Yongzhen, G. Shujing, L. Changguo, Harvesting of a phytoplankton zooplankton model, Nonlinear Anal. Real World Appl. 11 (2010) 3608.

* L.C. Barros, R.C. Bassanezi, P.A. Tonelli, Fuzzy modelling in population dynamics, Ecol. Model. 128 (2000) 27.

* L.S. Pontryagin's, V.G. Boltyonsku, R.V. Gamkrelidre, E.F. Mishchenko, The Mathematical Theory of Optimal Process, Wiley, New York, 1962.

* M. Guo, X. Xu, R. Li, Impulsive functional differential inclusions and fuzzy population models, Fuzzy Sets Syst. 138 (2003) 601.

* R. Hannesson, Optimal harvesting of ecologically interdependent fish species, J.Environ. Econ. Manag. 10 (1982) 329.

* R.C. Bassanezi, L.C. Barros, A. Tonelli, Attractors and asymptotic stability for fuzzy dynamical systems, Fuzzy Sets Syst. 113 (2000) 473.

* W. Li, K. Wang, H. Su, Optimal harvesting policy for stochastic logistic population model, Appl. Math. comput. 218 (2011) 157.

* W. Li, K. Wang, Optimal harvesting policy for general stochastic logistic population model, J. Math. Anal. Appl. 368 (2010) 420. 